\title{
Impact of $\mathrm{Na} / \mathrm{Al}$ Ratio on the Extent of Alkali-Activation Reaction: Non-linearity and Diminishing Returns
}

\author{
Omar Abdelrahman and Nishant Garg * \\ Department of Civil and Environmental Engineering, University of Illinois at Urbana-Champaign, Urbana, IL, United States
}

\section{OPEN ACCESS}

Edited by:

Cristina Leonelli,

University of Modena and Reggio

Emilia, Italy

Reviewed by:

Kenneth John MacKenzie, MacDiarmid Institute for Advanced

Materials and Nanotechnology,

New Zealand

Duangrudee Chaysuwan,

Kasetsart University, Thailand

*Correspondence:

Nishant Garg

nishantg@illinois.edu

Specialty section:

This article was submitted to

Solid State Chemistry,

a section of the journal

Frontiers in Chemistry

Received: 31 October 2021 Accepted: 10 December 2021

Published: 03 January 2022

Citation:

Abdelrahman O and Garg N (2022) Impact of Na/Al Ratio on the Extent of Alkali-Activation Reaction: Nonlinearity and Diminishing Returns.

Front. Chem. 9:806532.

doi: 10.3389/fchem.2021.806532
To address the high $\mathrm{CO}_{2}$ footprint associated with cement production, many alternative, sustainable binders are now gaining worldwide attention-including alkali-activated materials. The alkali-activation reaction of metakaolin is a fairly complex process involving transformation of one amorphous reactant (precursor metakaolin) into another amorphous product or products (N-A-S-H gel and/or disordered zeolite type phases). In spite of this complexity, researchers in the past 2 decades have gained significant knowledge on the nature of this reaction at multiple scales. Understanding and developing a clear relationship between the alkalinity of the mix and the extent of reaction is of high interest for practical applications. However, detailed and thorough investigations on this important relationship are limited. Here, in this study, we address this gap by systematically investigating a series of alkali-activated materials samples with a wide range of $\mathrm{Na} / \mathrm{Al}$ ratios $(0.5-1.8)$ using seven different yet complementary analytical techniques (isothermal calorimetry, FTIR, XRD, TGA, NMR, and Raman imaging). Applied in tandem, these tools reveal a clear but non-linear relationship between the Na/Al ratio and the extent of alkali-activation reaction indicating diminishing returns at higher Na/Al ratios, where higher $\mathrm{Na} / \mathrm{Al}$ ratios cause an increase in the degree of reaction until a certain point at which the increase in Na/Al ratio does not significantly affect the reaction kinetics, but may affect the gel polymerization. These findings could potentially aid decision making for commercial applications of AAMs where alkalinity of the mix is an important parameter for performance as well as safety.

Keywords: alkali-activated materials, geopolymers, metakaolin, isothermal calorimetry, FTIR, XRD, NMR, TGA

\section{INTRODUCTION}

The global environmental impact of the cement industry is resulting in an increasing concern and dedication towards finding more sustainable alternatives for Portland cement. One of the most promising alternatives is alkali-activated materials (AAM) (Rivera et al., 2021; van Deventer et al., 2021), also referred to as geopolymers. The terms geopolymers (Davidovits, 1989), inorganic polymers (Van Wazer, 1970), alkali-activated cement (Palomo and López de la Fuente, 2003), and geocement (Krivenko, 1994) are all used to describe these binding materials, which can provide comparable, or higher performance than the traditional cementitious binders (Wang et al., 2019; Alzeer et al., 2021) with significantly lower greenhouse emissions (Gartner, 2004; Palomo et al., 2021).

These binders are manufactured by activating an aluminosilicate precursor such as metakaolin, blast furnace slag, or fly ash using an alkaline solution, mostly sodium hydroxide or silicate solutions. 
The chemical composition of the activation product depends on the used raw materials. High-calcium alkali-activated materials such as slag or class $\mathrm{C}$ fly ash result in the formation of an aluminum-substituted C-A-S-H gel (Escalante-García et al., 2003; Fernández-Jiménez et al., 2003), with the possibility of some replacement of $\mathrm{Ca}^{2+}$ by $\mathrm{Na}^{+}$, leading to the formation of both sodium- and aluminum-substituted C-(N)-A-S-H type gel (Myers et al., 2013; Sankar et al., 2019). On the other hand, the activation of low-calcium or calcium-free materials such as metakaolin or class $\mathrm{F}$ fly ash results in the formation of a $\mathrm{N}-\mathrm{A}-\mathrm{S}-\mathrm{H}$ gel, an amorphous binder that consists of a random network of tetrahedral $\mathrm{SiO}_{4}$ molecules linked to $\mathrm{AlO}_{4}{ }^{-}$units by sharing oxygen atoms, with $\mathrm{Na}^{+}$ions balancing the negative charge of the $\mathrm{Al}^{3+}$ in IV-fold coordination (Davidovits, 1989).

The activation process, as well as the mechanical and chemical properties of the produced binder, are dependent on several synthesis parameters such as the nature of the aluminosilicate source, the activating solution used, mix design, and curing conditions. (Rees et al., 2007; Silva et al., 2007; Granizo et al., 2014; Ghanbari et al., 2017). Another parameter that is also of equal importance for the alkali-activated binder formation is the alkalinity, which can be expressed as the molar ratio of $\mathrm{M} / \mathrm{Al}$ or $\mathrm{M} / \mathrm{Si}$, where $\mathrm{M}$ represents the alkali ions, e.g., Na or K (De Vargas et al., 2011; Granizo et al., 2014).

Previous research has revealed to some extent the effect of the concentration of the alkaline solution on the formation process of the binders (Granizo and Blanco, 1998; Yao et al., 2009; Zhang et al., 2012; Zhang et al., 2013; Sun and Vollpracht, 2018; Hou et al., 2019; Król et al., 2019). It has been found, using various analytical techniques, that the increase in alkaline solution concentration can generally increase the reaction rate and the extent of the activation reaction. At extremely high dosage rates of alkalis, the nanoscale ordering and the polymerization of the silicate network of the C-(N)-A-S-H gel have been found to be affected (Garg et al., 2019). However, the precise effect of the activating solution's alkalinity, which can be represented by the mix's $\mathrm{Na} / \mathrm{Al}$ ratio, on the phase assemblage and structure of the produced gel is yet to be fully understood.

In this study, a multi-technique correlative analysis was performed on alkali-activated binder samples manufactured using metakaolin as the aluminosilicate source precursor, with variable alkaline concentrations resulting in binders with a wide range of $\mathrm{Na} / \mathrm{Al}$ ratios (0.5-1.8). All other parameters, such as $\mathrm{Si} / \mathrm{Al}$ and water/binder ratios, were kept constant for all the mixes (1.5 and 1.0, respectively). The techniques used include isothermal calorimetry, FourierTransform infrared spectroscopy (FTIR), X-ray diffraction analysis (XRD), thermogravimetric analysis (TGA), ${ }^{27} \mathrm{Al}$ and ${ }^{23} \mathrm{Na}$ magic angle spinning solid-state nuclear magnetic resonance (MAS NMR), and Raman spectroscopy and imaging. Applying these different yet complementary techniques provides a thorough understanding of the activation reaction kinetics and the chemical and crystalline structure of the produced gel. The acquired results indicate the increasing formation rate of the $\mathrm{N}$-A$\mathrm{S}-\mathrm{H}$ gel with increasing the $\mathrm{Na} / \mathrm{Al}$ ratio, as well as the greater extent of the activation of the metakaolin precursor.
Correlations between the different techniques were deduced by analyzing and comparing each technique's results. Specifically, a strong correlation was found between the cumulative heat from isothermal calorimetry and the Si-O-T peak position in the FTIR data (observed in the region of $1,200-950 \mathrm{~cm}^{-1}$ wavenumber), suggesting that FTIR Si-O-T peak position is a good indicator of the overall alkali-activation. In addition, the alkalinity was found to affect the peak position of XRD's zeolite phase and NMR's $\mathrm{Al}^{(4)}$ coordination in a very similar manner. Also, the zeolite/ anatase peak ratio was compared to NMR's $\mathrm{Al}^{(6)} / \mathrm{Al}^{(4)}$ ratio, and a correlation between the two ratios was deduced, recognizing that each ratio has a different sensitivity to changes in alkalinity at different $\mathrm{Na} / \mathrm{Al}$ ranges. Finally, and most importantly, all techniques pointed to the fact that there's a non-linear relationship between $\mathrm{Na} / \mathrm{Al}$ ratio and the extent of alkali-activation reaction.

\section{MATERIALS AND METHODS}

\section{Sample Preparation}

The metakaolin used as the solid precursor to synthesize the AAM mixtures was MetaMax ${ }^{\circledR}$ manufactured by BASF (New Jersey, United States). The activating solution was prepared using sodium hydroxide pellets manufactured by MACRON Fine Chemicals and sodium silicate solution ( $\mathrm{D}$ solution by $\mathrm{PQ}^{\circledR}$ ). To prepare the mixes, $\mathrm{NaOH}$ and $\mathrm{Na}_{2} \mathrm{SiO}_{3}$ were mixed first and left to cool down to room temperature before adding the precursor. The ingredients were mixed in a Vortex mixer for 1 minute, left to rest for $30 \mathrm{~s}$, and then mixed again for another minute at a speed of 2,500 rpm. After that, the slurry was cast into a silicon mold to form cubic samples of $1 \mathrm{~cm}$ sides. The samples were then sealed with a parafilm, and left to cure at room temperature. At the desired age, the samples were extracted and tested. The AAM mixtures all had the same $\mathrm{Si} / \mathrm{Al}$ molar ratio of 1.5 and water/binder ratio of 1.0. The $\mathrm{Na} / \mathrm{Al}$ molar ratio was adjusted for the different mixtures ranging from 0.5 to 1.8. This single ratio was adjusted by manipulating the amount of $\mathrm{NaOH}$ added to the mix while keeping all the other components constant for all the mixes.

\section{Experimental Procedures}

Isothermal calorimetry tests were conducted on the alkaliactivated binder samples using a TAM Air isothermal calorimeter manufactured by TA Instruments, United States. The samples were all manufactured using the same precursor mass of $5 \mathrm{~g}$. The samples were mixed, shaken, and then rapidly poured into plastic HDPE ampoules and placed inside the instrument. The temperature was set at $22^{\circ} \mathrm{C}$, and the data were collected for the first $72 \mathrm{~h}$ in which both the heat flow and the cumulative heat were monitored. This duration was deemed sufficient for studying the kinetics and the extent of the reaction of the alkali-activated binders. However, the first $45 \mathrm{~min}$ of data were disregarded because of the disturbance in the baseline caused by the insertion of the sample holders. It was found that $45 \mathrm{~min}$ is 
the time required by the instrument to re-stabilize after this disturbance.

IR spectra were measured using a PerkinElmer FTIR Frontier spectrometer with an attached universal attenuated total reflectance (UATR) polarization accessory. The spectra were collected in the region of $4,000-400 \mathrm{~cm}^{-1}$ for 30 scans per sample with a spectral resolution of $4 \mathrm{~cm}^{-1}$. FTIR scans were performed on the constituents of the binder (metakaolin, $\mathrm{NaOH}$, and PQD sodium silicate solution) and the AAM mixes having different $\mathrm{Na} / \mathrm{Al}$ ratios in the range of $0.5-1.8$. The samples were scanned at different time intervals, starting from $15 \mathrm{~min}$ after mixing up to 45 days.

X-Ray Diffraction was performed on the powdered samples at the age of 3 months to get their mineralogical composition. The instrument used was Bruker D8 Advance Plus (CuKa radiation, $40 \mathrm{kV}, 40 \mathrm{~mA}$ ) equipped with an EIGER2 R $500 \mathrm{~K}$ detector. The measuring time was $40 \mathrm{~min}$ per sample, with a $2 \theta$ range of $5-70^{\circ}$ and a step size of $0.01^{\circ}$.

Thermogravimetric analysis tests were performed on the AAM samples at the age of 3 months using the Q50 TGA instrument by TA Instruments, United States. The samples (16-20 mg) were subjected to a temperatures range of $23-800^{\circ} \mathrm{C}$ at a heating rate of $10^{\circ} \mathrm{C}$ per minute and in a nitrogen flow of $60 \mathrm{ml}$ per minute. The instrument measured the sample's weight loss and calculated its derivative as a function of temperature. These data were used to quantify and compare the amount of the geopolymer gel formulated in each sample.

Single-pulse ${ }^{27}$ Al MAS solid-state NMR tests were performed on the AAM samples at the age of 4 months using a VSN750NB nuclear magnetic resonance spectrometer (Agilent, United States) with a frequency of $750 \mathrm{MHz}(17.6 \mathrm{~T})$. The powder samples were placed into $4 \mathrm{~mm}$ diameter rotors and installed inside the instrument's T3 Triple Res HXY solids probe. The spinning speed was set at $13 \mathrm{kHz}$ for metakaolin and $9 \mathrm{kHz}$ for the AAM samples. Higher spinning speed was used for metakaolin to avoid overlapping the spinning sideband peaks with the peaks of the different $\mathrm{Al}$ coordination environments found in metakaolin. A total of 1,024 scans were taken for each sample with a relaxation delay time of one second. The chemical shifts were measured with respect to zero reference from an aluminum nitrate solution $\left(\mathrm{Al}\left(\mathrm{NO}_{3}\right)_{3}\right)$. For a direct comparison, the peak intensities in the final spectra in all the figures have been normalized to the sample mass packed in the NMR rotors.

Single-pulse ${ }^{23} \mathrm{Na}$ MAS solid-state NMR tests were also performed on the same AAM samples using a UI300 nuclear magnetic resonance spectrometer (Varian, USA) with a frequency of $300 \mathrm{MHz}(7.05 \mathrm{~T})$. The spinning speed was set at $10 \mathrm{kHz}$, and a total of 4,000 scans were taken for each sample with a relaxation delay time of $1 \mathrm{~s}$. The chemical shifts were measured with respect to zero reference from sodium chloride solution $(\mathrm{NaCl})$. The peak intensities in the final spectra in all the figures have also been normalized to the sample mass packed in the NMR rotors.

Finally, confocal Raman spectra and images were collected using a WITec Alpha 300 series SNOM confocal microscope on 7 day old AAM samples. A laser with a wavelength of $532 \mathrm{~nm}$ and an excitation power of $7 \mathrm{~mW}$ was used, with a grating of $600 \mathrm{~g} /$ mm coupled with a charged coupled device (CCD). The spectral resolution was $4.9 \mathrm{~cm}^{-1}$, and the spectra were acquired in the wavenumber range of $0-3,700 \mathrm{~cm}^{-1}$. The Raman spectra were collected on a $1 \mathrm{~mm} \times 1 \mathrm{~mm}$ area with a total points number of 22,500 per image, resulting in a lateral resolution of $\sim 6.7 \mu \mathrm{m}$. A 20X objective lens was used, with a working distance of $2.2 \mathrm{~mm}$ and a numerical aperture of 0.5 . The integration time was set to $0.1 \mathrm{~s} /$ point totaling around $38 \mathrm{~min}$ per sample for these acquisition conditions.

\section{RESULTS}

\section{Reaction Kinetics via Isothermal Calorimetry}

The rate and extent of the reaction are of significant importance in describing the alkali-activation process. A calorimetric characterization technique can provide real-time information about the reaction while it is running, which has a significant advantage over other techniques that acquire data in a discontinuous manner (Provis et al., 2005; Khale and Chaudhary, 2007). Isothermal calorimetry provides the heat flow rate during the reaction process, which serves as an indication for the reaction rate, and the cumulative emitted heat, which can represent the amount of metakaolin that has reacted in each of the different mixes. Recently, isothermal calorimetry has been successfully employed to study the reaction kinetics of alkali-activated slags, where it has been found highly complementary to other advanced X-ray (Garg and White, 2017) and Neutron scattering analysis (Gong et al., 2019).

Here, isothermal calorimetry was performed on the AAM samples for $72 \mathrm{~h}$, which can be considered sufficient to monitor the fundamental region of the alkali-activation process. Figure 1 shows the acquired results for all the samples. The recorded heat flow is shown in Figure 1A, in which two exothermal peaks can be observed. The initial exothermal peak, which typically appears as soon as the alkaline solution is added to the precursor, is not fully observable here as the samples were already mixed before placing them in the calorimeter, and also because of the disregard of the first $45 \mathrm{~min}$ of data until the baseline was stabilized. However, the decline of this peak can be clearly observed in the first few minutes of the recorded data.

A second exothermic peak is observed sometime later than the first one, ranging from just a few minutes for the samples with high $\mathrm{Na} / \mathrm{Al}$ ratios to more than 10 hours for those with relatively lower ratios, which is similar to what is observed in previous literature (Yao et al., 2009; Zhang et al., 2013). As for the two samples with the lowest $\mathrm{Na} / \mathrm{Al}$ ratios $(0.6$ and 0.5$)$, the two peaks are not fully observed. Only the decline of the first peak can be seen in the 0.6 sample, without a trace of a second peak. The 0.5 sample, however, does not show any of the peaks at all, indicating very little activation reaction occurring in the mix.

The cumulative heat generated by the reaction in the samples is plotted in Figure 1B. The sample with the lowest $\mathrm{Na} / \mathrm{Al}$ ratio of 0.5 resulted in very little overall cumulative heat. As the $\mathrm{Na} / \mathrm{Al}$ ratio increased up to 1.8 , the cumulative generated heat increased 

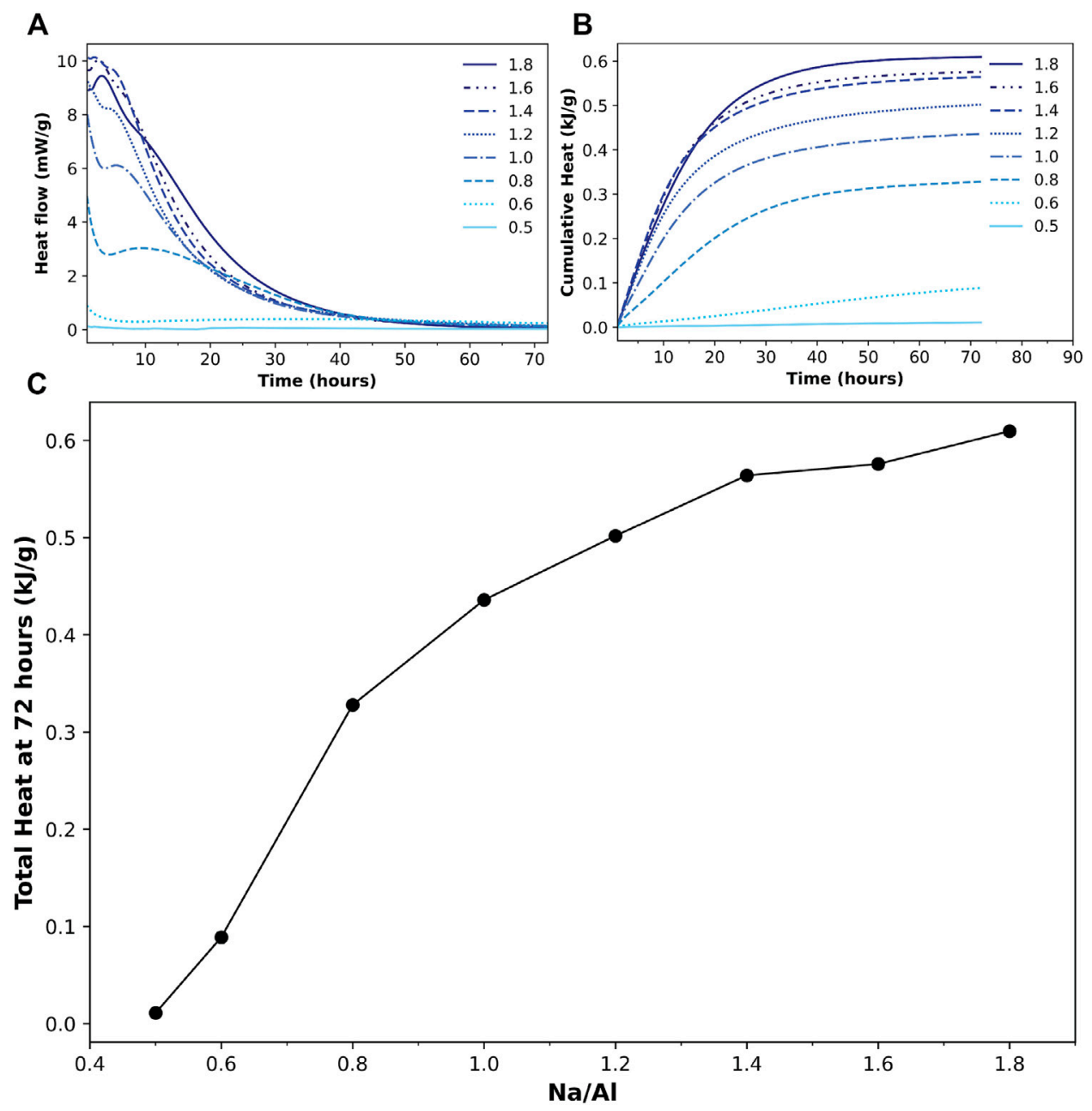

FIGURE 1 | (A) Heat flow and (B) cumulative heat results from isothermal calorimetry tests for $72 \mathrm{~h}$ on alkali-activated metakaolin samples with various $\mathrm{Na} / \mathrm{Al}$ ratios, indicated in figure (0.5-1.8). (C) The total heat generated after $72 \mathrm{~h}$ of activation for different $\mathrm{Na} / \mathrm{Al}$ ratios. The line is a guide to the eye.

accordingly. A correlation between the $\mathrm{Na} / \mathrm{Al}$ ratio and the total cumulative heat after $72 \mathrm{~h}$ of reaction is plotted in Figure 1C. This plot clearly shows the increasing cumulative heat with the increase of the mixes' alkalinity, which indicates a greater extent of alkali-activation reaction as the $\mathrm{Na} / \mathrm{Al}$ ratio is increased.

\section{Reaction Kinetics via FTIR}

Infrared spectroscopic techniques have been widely used to study different aluminosilicate structures. FTIR has proven to be very successful in identifying the different zeolite structures based on the analysis of molecules vibration (Mozgawa, 2001), which makes this method useful in analyzing materials with amorphous phases (Król et al., 2012).

The results of FTIR scans on various AAM samples are presented in Figure 2. The FTIR spectra of the main constituents of the mixes (metakaolin, $\mathrm{NaOH}$, and PQD sodium silicate solution) along with the AAM samples of $\mathrm{Na}$ / $\mathrm{Al}$ ratios of $0.5-1.8$, scanned $15 \mathrm{~min}$ after mixing, are shown in Figure 2A. The bands in the range of $1,100-400 \mathrm{~cm}^{-1}$ represent the aluminosilicate structure of the material. A specific peak of interest is the peak in the region of $1,200-950 \mathrm{~cm}^{-1}$ observed in metakaolin and in all the AAM samples. This peak represents the primary Si-O-T asymmetric stretching vibration (Stubičan and Roy, 1961; Król et al., 2019; Biel et al., 2020).

In the unreacted metakaolin powder, this peak is located at a wavenumber of $1,071 \mathrm{~cm}^{-1}$. After activation, it is found that the band gradually shifts towards more negative wavenumber values as the $\mathrm{Na} / \mathrm{Al}$ ratio increases, ranging from $1,014 \mathrm{~cm}^{-1}$ at a $\mathrm{Na} / \mathrm{Al}$ ratio of $0.6-931 \mathrm{~cm}^{-1}$ at a $\mathrm{Na} / \mathrm{Al}$ ratio of 1.8 . Figure $2 \mathrm{~B}$ shows the position of this peak as a function of the $\mathrm{Na} / \mathrm{Al}$ ratio for all the tested samples at different ages. This negative shift of the band position in the high $\mathrm{Na} / \mathrm{Al}$ ratio mixes is the result of the lower presence of component bands at the higher wavenumbers, which are associated with the amount of unreacted metakaolin present in the sample (Król et al., 2016). Thus, the shift in the Si-O-T peak position can serve as an indication of the extent of the alkaliactivation reaction occurring in each sample, showing again, a clear increase in the reaction as the alkalinity of the mix increases. 

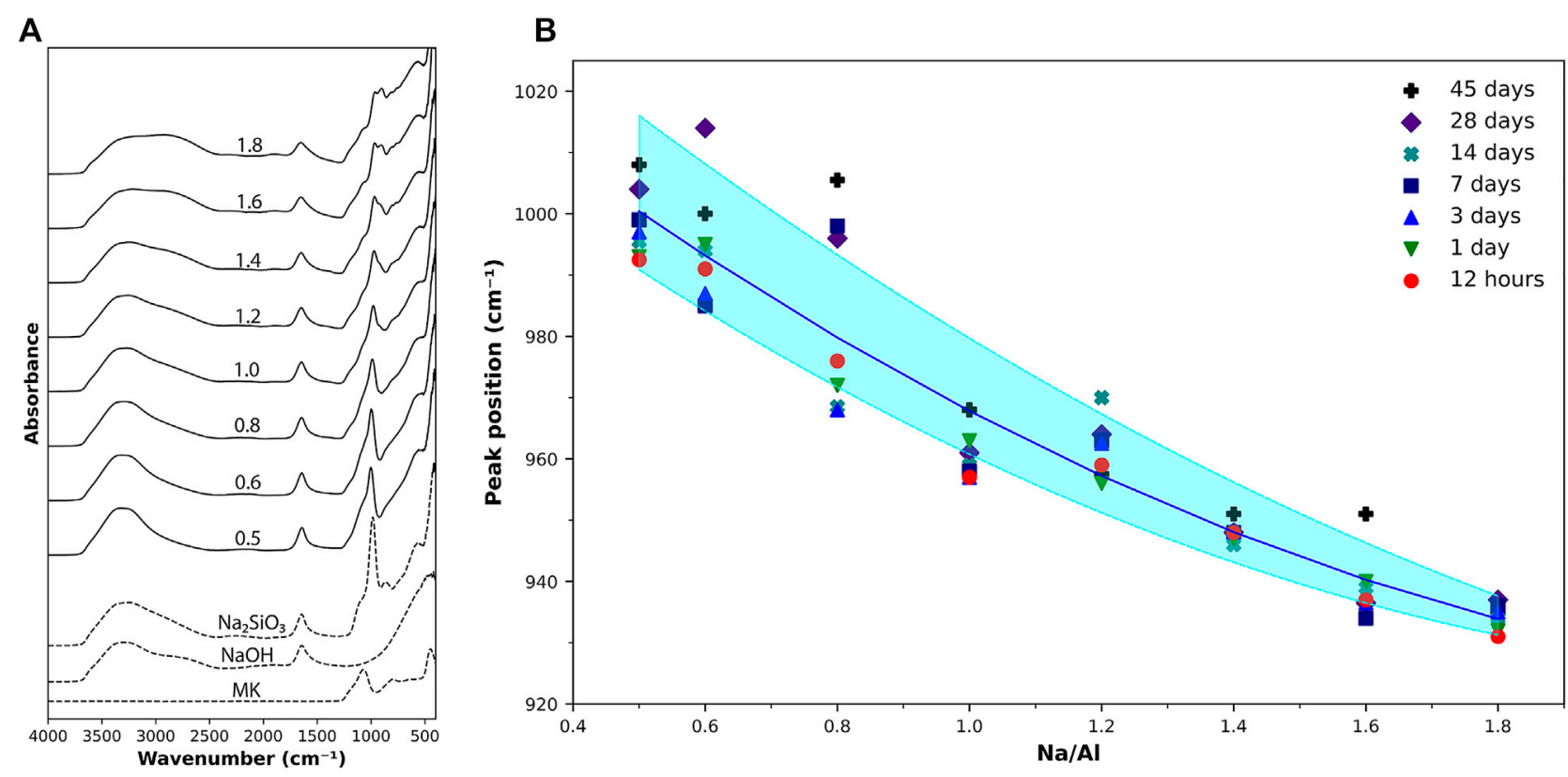

FIGURE 2 | (A) FTIR scan results on metakaolin, activating solutions, and AAM samples with various Na/Al ratios (as listed) scanned 15 min after activation. (B) Si$\mathrm{O}-\mathrm{T}$ peak position for various $\mathrm{Na} / \mathrm{Al}$ ratios at different ages. The shaded region provides a guide to the eye of how the Na/Al ratio affects the peak position.

\section{Phase Assemblage via XRD}

$\mathrm{X}$-Ray Diffractometry (XRD) is a crucial technique for detecting alkali-activated binders' mineralogical phase assemblage. The zeolitic binder phase formed by the alkali-activation of metakaolin has been often described as "X-Ray amorphous" (Barbosa et al., 2000; Provis et al., 2005). Studies have shown that the primary growth units during the zeolite formation are particles around 2-5 nm in size (Nikolakis et al., 2000; Kragten et al., 2003). This length scale is below the detection limit of XRD. That is why no observable peaks are usually detected on the XRD spectrum of zeolitic geopolymers. However, a broad hump, centered at around $27-29^{\circ} 2 \theta$, is a typical feature observed in the XRD diffraction pattern of alkali-activated materials. (Alonso and Palomo, 2001; Rowles and O'Connor, 2003; Yunsheng et al., 2010; Li et al., 2019; Alventosa and White, 2021). This peak has been considered the distinguishing feature of geopolymers as it was present in any geopolymer binder regardless of the type of precursor used, activating solution, and curing conditions (Provis et al., 2005).

The diffraction patterns of metakaolin and the 3 month old AAM powders having different $\mathrm{Na} / \mathrm{Al}$ ratios are plotted in Figure 3A. The metakaolin spectrum shows a highly amorphous structure, except for a highly distinctive peak at an angle $2 \theta$ of around $25^{\circ}$, along with a series of smaller distributed peaks. These peaks match the exact spectrum of anatase $\left(\mathrm{TiO}_{2}\right.$, PDF number 01-076-0325) (Howard et al., 1991), which is present as an impurity in the metakaolin precursor. Despite the modest anatase content inside the metakaolin, it highly dominates the XRD spectrum because of its highly crystalline structure (Thamaphat et al., 2008). In addition to these peaks, the diffractogram of unreacted metakaolin shows a broad amorphous hump at around $22^{\circ} 2 \theta$. This hump is also observed in the AAM samples having very low $\mathrm{Na} / \mathrm{Al}$ ratios, indicating the presence of high amounts of unreacted metakaolin. This observation is in good agreement with previous research work in AAM mixes that had low quantities of activating solution used, causing only partial activation of metakaolin (Rowles and O'Connor, 2003).

For the XRD spectrum of the alkali-activated metakaolin, the anatase peaks are also observed after activation since they are not involved in the reaction process. The hump representing zeolites and/or a N-A-S-H type gel can be observed in the $2 \theta$ range of $27-29^{\circ}$. It is observed that the height of the hump increases with the increase in the $\mathrm{Na} / \mathrm{Al}$ ratio, accompanied by a decrease in its width. The increase in the height of the zeolite peak, normalized to the anatase peak, with increasing alkalinity is plotted in Figure 3B. This peak sharpening effect, which was also observed in previous XRD analysis on AAMs (Yang et al., 2000; Zhan et al., 2002), is due to an increased level of crystallization within the product gel, causing the formation of larger crystals that are easier to detect by diffraction.

In addition to the change in the hump's sharpness, it is also observed that the hump is shifting gradually towards higher $2 \theta$ angles as the $\mathrm{Na} / \mathrm{Al}$ ratio increases, as shown in Figure 3C. This behavior was also observed in previous work (Williams et al., 2011; Hou et al., 2019). In low Na/Al ratios, the centroid of the zeolite peak is at a relatively low $2 \theta$ angle due to the limited activation reaction that occurred in the mix and the presence of considerable amounts of unreacted metakaolin. This unreacted metakaolin forms a high peak component at around $22^{\circ} 2 \theta$, pulling the centroid of the hump towards lower $2 \theta$ values. For higher $\mathrm{Na} / \mathrm{Al}$ ratios, a higher amount of metakaolin is activated, causing the metakaolin component to go down and the centroid 

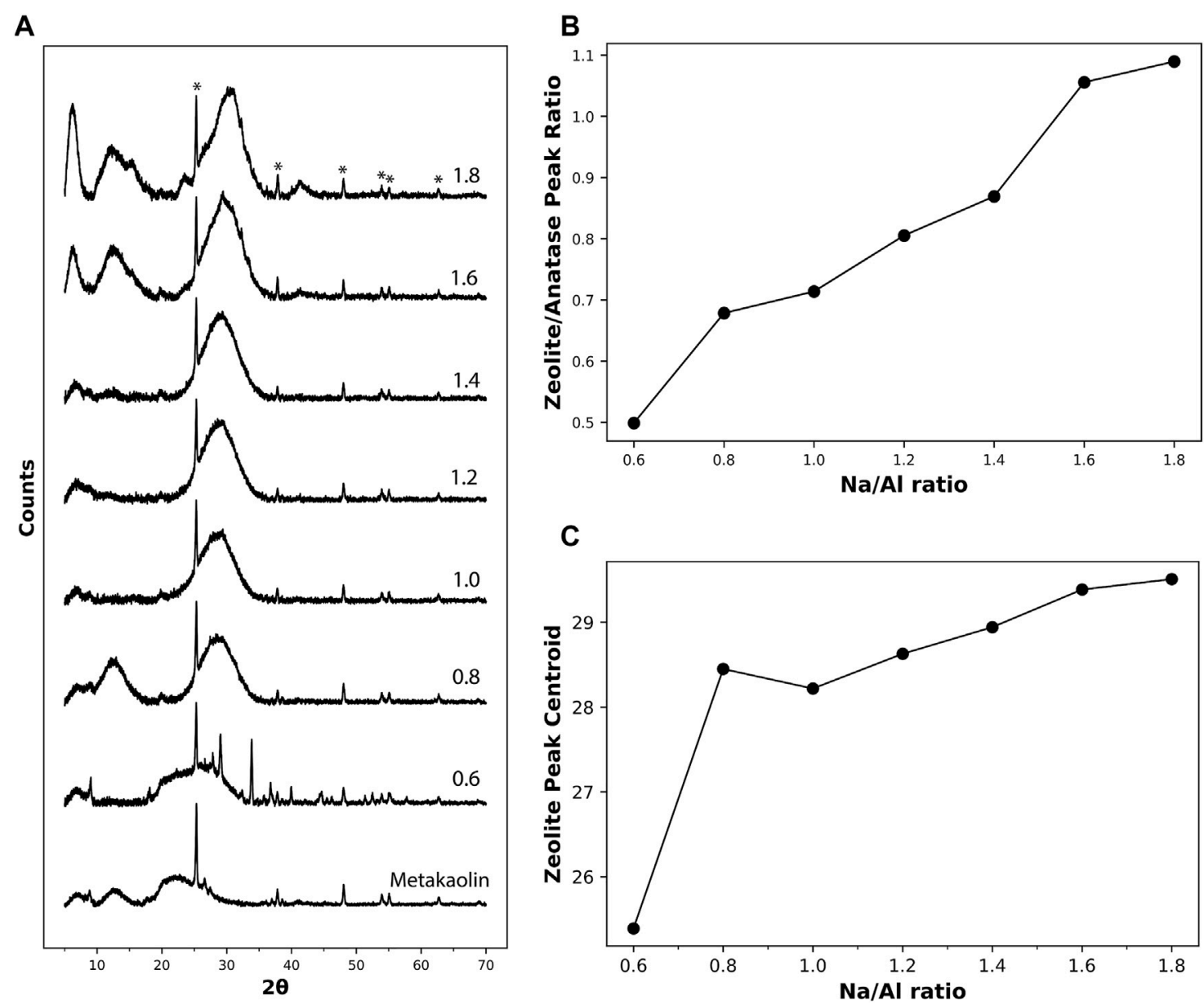

FIGURE 3 | (A) XRD diffractograms of metakaolin precursor and the different 3 month old AAM samples with Na/Al ratios ranging from 0.6 to 1.8. (B) The ratio between the height of the zeolite XRD hump at $2 \theta \approx 29^{\circ}$ and the anatase's prominent peak at $2 \theta \approx 25^{\circ}$ for the different samples. (C) The location of the centroid of the peak representing zeolites for the different $\mathrm{Na} / \mathrm{Al}$ ratios. The peaks marked with (*) represent anatase $\left(\mathrm{TiO}_{2}, \mathrm{PDF}\right.$ number 01-076-0325).

of the hump to shift towards higher $2 \theta$ values. Thus, based on this observed behavior, the centroid location of the zeolite and/or $\mathrm{N}-\mathrm{A}-\mathrm{S}-\mathrm{H}$ gel hump could serve as an indication of the extent of the alkali-activation reaction.

\section{Phase Assemblage via TGA}

Thermogravimetric Analysis (TGA) has been used to quantify the amount of hydration products of different binders, which can be achieved by tracking the weight loss of the sample when subjected to an elevating temperature. The weight-loss behavior can be attributed to the amount of bound water inside the binder structure, where the weight loss percentage can represent the weight of water present, and the derivative of weight loss (DTG) can be used to identify the source of the water that is evaporating inside the sample (Nath et al., 2016). Previous research has identified the weight loss of water bound inside the N-A-S-H gel to be in the region between $85-135^{\circ} \mathrm{C}$ (Duxson et al., 2007b; Winnefeld et al., 2010; Rocha et al., 2018; Chaipanich et al., 2019).

TGA and DTG results of the 3 month old AAM samples are plotted in Figure 4. The weight loss percentage is shown in
Figure 4A along with each sample's $\mathrm{Na} / \mathrm{Al}$ ratio, and Figure 4B shows the derivative weight loss for the same samples. A direct relationship between the $\mathrm{Na} / \mathrm{Al}$ and the weight loss at a temperature of $400^{\circ} \mathrm{C}$ is shown in Figure $4 \mathrm{C}$. Temperatures above $400^{\circ} \mathrm{C}$ were not considered for this plot to remove any weight loss that could have occurred due to the presence of carbonation products that could have formed inside the samples. Weight loss of carbonation products is usually observed at temperatures of around $600^{\circ} \mathrm{C}$ (Abdalqader et al., 2015). The graph shows that the increase in $\mathrm{Na} / \mathrm{Al}$ ratio from 0.6 to 1.8 is accompanied by an increase in weight loss from 14.6 to $28.6 \%$. The higher weight loss can be attributed to the increase in the bound water inside the binder structure, which supports the finding that the amount of N-A-S-H gel increases with increasing $\mathrm{Na} / \mathrm{Al}$ ratio.

\section{${ }^{27}$ Al Local Environments via MAS NMR}

The molecular arrangements of the alkali-activated binders can be studied with solid-state MAS NMR, which has been proven to be of great value for the study of alkali-activated metakaolin in particular (Provis and Deventer, 2009). It was one of the first 

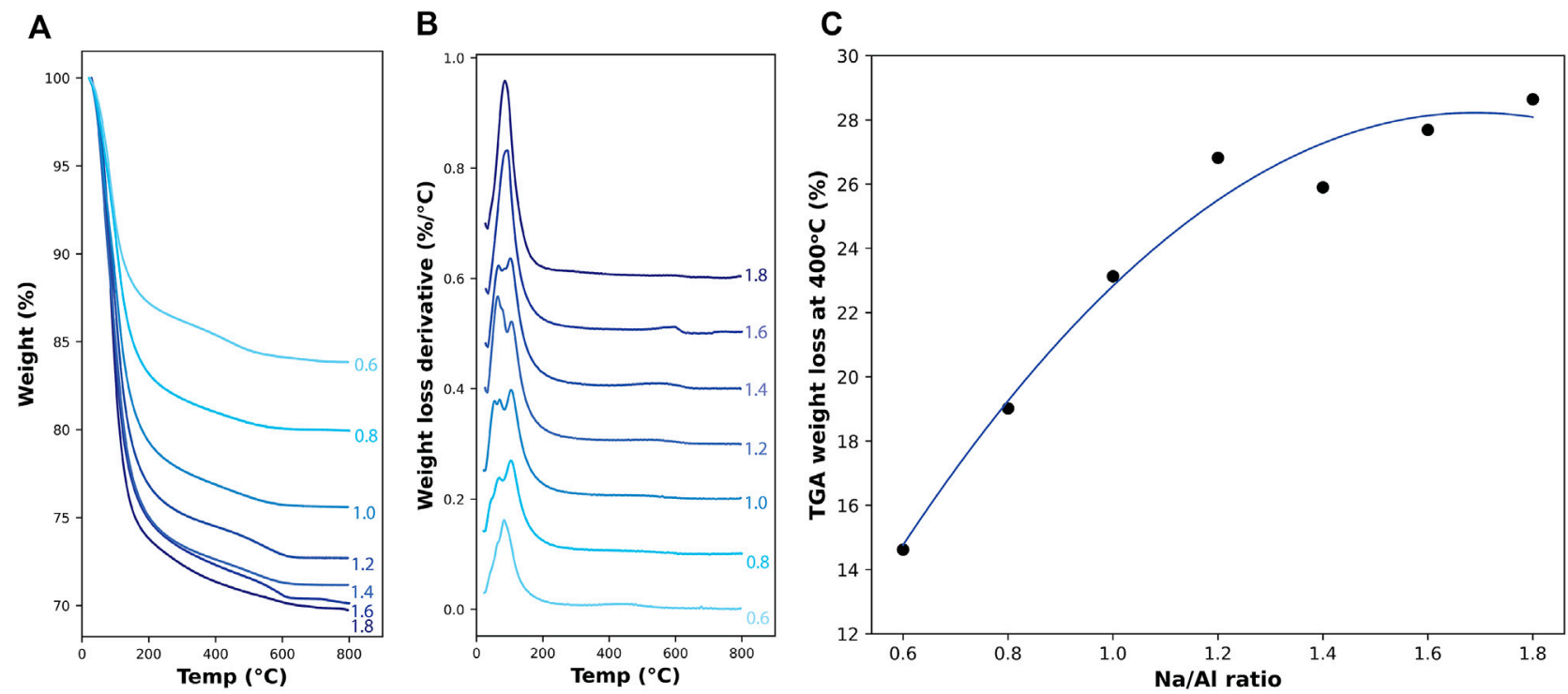

FIGURE 4 | TGA results on 3 month old AAM samples. (A) shows the percentage of weight loss and (B) shows the derivative weight loss with increasing temperature up to $800^{\circ} \mathrm{C}$. (C) shows the total percentage of weight lost in the samples at a temperature of $400^{\circ} \mathrm{C}$ for different $\mathrm{Na} / \mathrm{Al}$ ratios, with a second-degree polynomial best fit curve.

advanced analytical techniques to be applied for the study of alkali-activated metakaolin (Davidovits, 1988) and has become a widely used technique ever since (Barbosa et al., 2000; Singh et al., 2005; Rowles et al., 2007; Ruiz-Santaquiteria et al., 2012, 2013).

${ }^{27} \mathrm{Al}$ MAS NMR results can be used to indicate the extent of reaction of metakaolin into geopolymer gel (Provis and Deventer, 2009). The coordination of Al varies with the change of the number of oxygen atoms immediately bonded to each $\mathrm{Al}$ position. This results in $\mathrm{Al}$ coordination environments of 4, 5, and 6. Since the Loewenstein avoidance principle (Loewenstein, 1954) states that Al-O-Al bonds cannot exist, it is safe to assume that the coordination number refers to the number of $\mathrm{SiO}_{4}$ tetrahedra that can connect to an $\mathrm{AlO}_{\mathrm{n}}$ moiety, as only silicon can be the next-nearest neighbor (Rowles et al., 2007). The ${ }^{27} \mathrm{Al}$ chemical shifts defining $\mathrm{Al}^{(4)}, \mathrm{Al}^{(5)}$, and $\mathrm{Al}^{(6)}$ are well separated and allow for the coordination number of $\mathrm{AlO}_{\mathrm{n}}$ units to be clearly determined (Rowles et al., 2007; Vinet and Zhedanov, 2011).

The results of ${ }^{27} \mathrm{Al}$ MAS NMR scans on metakaolin precursor exhibited three broad resonances at 54,33, and $4.2 \mathrm{ppm}$, as seen in Figure 5A, which are assigned to $\mathrm{Al}^{(4)}, \mathrm{Al}^{(5)}$, and $\mathrm{Al}^{(6)}$ coordination environments, respectively (Rocha, 1999; Duxson et al., 2007a; Fernandez et al., 2011). The presence of multiple coordination environments in metakaolin and its amorphous nature enhances its reactivity and helps initiate the activation reaction (Granizo et al., 2000). Specifically, $\mathrm{Al}^{(5)}$ sites have been recently reported to contribute significantly to the reactivity and dissolution of metakaolin (Garg and Skibsted, 2019). After the reaction, however, the ${ }^{27} \mathrm{Al}$ MAS NMR results for the 4 month old alkali-activated metakaolin samples are dominated by a single resonance in the 58-62 ppm range (Figure 5A), suggesting an almost complete transformation from the $\mathrm{Al}$ distribution observed in metakaolin to only $\mathrm{Al}^{(4)}$ coordination. A negative shift was observed in the $\mathrm{Al}^{(4)}$ resonance in the series of ${ }^{27} \mathrm{Al}$ MAS NMR spectra of the alkali-activated metakaolin with varying $\mathrm{Na} / \mathrm{Al}$ ratios. The $\mathrm{Al}^{(4)}$ resonance peak shifted from $58.3 \mathrm{ppm}$ for $\mathrm{Na} /$ $\mathrm{Al}$ ratio of 0.6 , to $61.8 \mathrm{ppm}$ for $\mathrm{Na} / \mathrm{Al}$ ratio of 1.8 . This relationship between the $\mathrm{Na} / \mathrm{Al}$ ratio and the position of the $\mathrm{Al}^{(4)}$ resonance peak is presented in Figure 5B. This negative shift is similar to what is found in recent work (Balzer et al., 2020), and it can be explained by the re-arrangement of the tetrahedral units after the hydrolysis of the T-O-T bonds and the formation of more $\mathrm{Q}^{3} \mathrm{AlOH}$, which has a higher ppm value than the $\mathrm{Q}^{4} \mathrm{Al}$ (Zeng et al., 2000).

Figure 5A also shows low-intensity resonance peaks representing $\mathrm{Al}^{(5)}$ and $\mathrm{Al}^{(6)}$ coordination that can still be observed in the mixes with lower $\mathrm{Na} / \mathrm{Al}$ ratios. Their intensity decreases as the $\mathrm{Na} / \mathrm{Al}$ ratio increases until they disappear at high-Na mixes. These peaks serve as an indication of the amount of unreacted metakaolin in the mix (Duxson et al., 2005; Rowles et al., 2007). Thus, a ratio of the peak intensity of $\left(\mathrm{Al}^{(5)}+\mathrm{Al}^{(6)}\right)$ to that of $\mathrm{Al}^{(4)}$ can be used to estimate the relative amount of unreacted metakaolin in each mix. This ratio is plotted in Figure 5C with respect to each mix's $\mathrm{Na} / \mathrm{Al}$ ratio. A clear trend that can be observed which shows the decrease in unreacted metakaolin with the increase of $\mathrm{Na} / \mathrm{Al}$ ratio.

\section{${ }^{23} \mathrm{Na}$ MAS NMR}

Since $\mathrm{Na}^{+}$ions are incorporated into the alkali-activated systems and the formulated NASH gel, the characterization of the ${ }^{23} \mathrm{Na}$ environment can provide additional valuable information about the extent of alkali-activation reactions of the different systems. Previous literature has identified that the bond of $\mathrm{Na}$ in AAM gel is in the form of $\mathrm{Na}\left(\mathrm{H}_{2} \mathrm{O}\right)_{\mathrm{n}}{ }^{+}$, where $\mathrm{n}=2-8$ (Škvára et al., 2009). However, the $\mathrm{Na}-\mathrm{O}$ bonds are more ionic and much weaker than $\mathrm{Si}-\mathrm{O}$ or A1-O bonds, and thus, the $\mathrm{Na}$ coordinations are often 

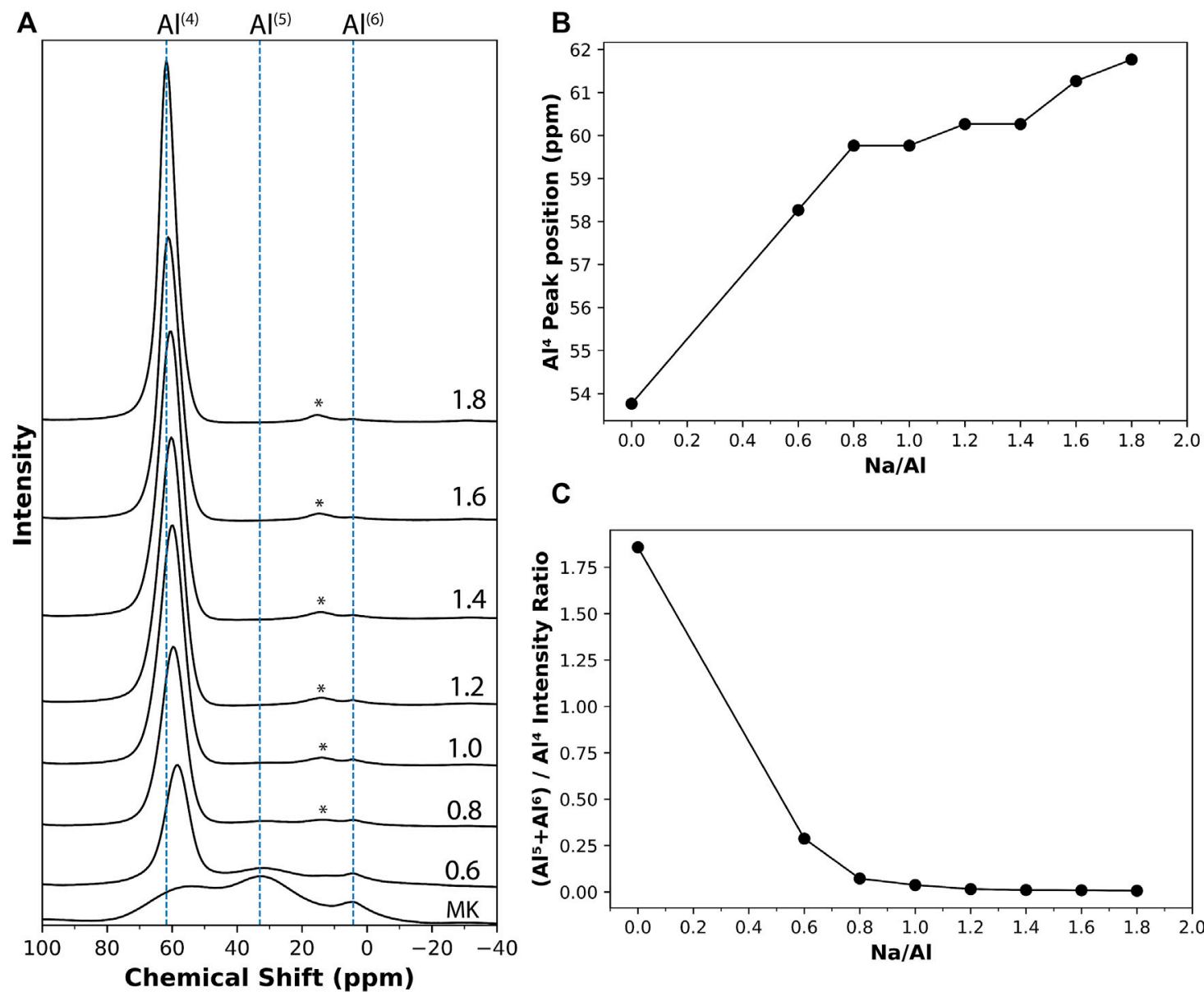

C

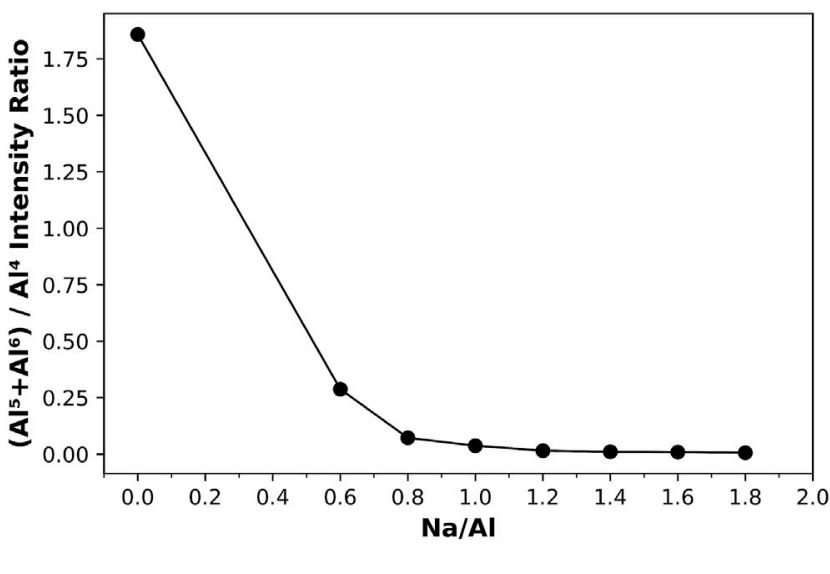

FIGURE 5 | (A) $)^{27} \mathrm{Al}$ solid-state MAS NMR results on metakaolin and different 4 month old AAM samples with varying Na/Al ratios (0.6-1.8), identified on each plot. The chemical shift values are referenced to $\mathrm{Al}\left(\mathrm{NO}_{3}\right)_{3}$ solution. The results were normalized according to the samples' weights. The peaks marked with (*) are spinning sidebands. (B) The change in the position of $\mathrm{Al}^{(4)}$ peak with respect to the $\mathrm{Na} / \mathrm{Al}$ ratio. (C) The $\mathrm{Al}^{(5)}+\mathrm{Al}^{(6)}$ to $\mathrm{Al}^{(4)}$ peak ratio for the different mixes.

believed to be ill-defined (Xue and Stebbins, 1993). This results in a broad peak, as observed by previous researchers testing ${ }^{23} \mathrm{Na}$ NMR resonance on AAMs (Duxson et al., 2005; Rowles et al., 2007; Walkley et al., 2016).

The results obtained from the ${ }^{23} \mathrm{Na}$ NMR tests on the AAM samples showed a single broad peak, as seen in Figure 6A. The position of this peak is seen to be shifting with the change in the $\mathrm{Na} / \mathrm{Al}$ ratio, ranging between $-9.62 \mathrm{ppm}$ and $-4.93 \mathrm{ppm}$ for $\mathrm{Na} / \mathrm{Al}$ ratios of 0.6 and 1.8 , respectively. Similar behavior was observed in previous research in which the peak position was found to shift with changes in the $\mathrm{NaOH}$ concentration (Rowles et al., 2007). The relationship between the peak position and the $\mathrm{Na} / \mathrm{Al}$ ratio is plotted in Figure 6B. It is believed that this shift can be attributed to the degree of polymerization of the structure, as the peak position is affected by the mean $\mathrm{N}-\mathrm{O}$ bond length and by the number of nonbridging oxygens per tetrahedrally coordinated cation $(\mathrm{NBO} / \mathrm{T})$ (Xue and Stebbins, 1993). So, the increase in the ${ }^{23}$ Na peak position observed with increasing the $\mathrm{Na} / \mathrm{Al}$ ratio potentially suggests that the mean $\mathrm{Na}-\mathrm{O}$ bond length decreases and the $\mathrm{NBO} / \mathrm{T}$ increases. Thus, although the extent of reaction increases with increasing the $\mathrm{Na} / \mathrm{Al}$ ratio, the N-A-S-H gel is likely becoming less polymerized, which could lead to a microstructure that is more susceptible to leaching. Recent research has also observed similar behaviors for C-N-A-S-H gel where increasing alkalinity of the activator results in lower gel polymerization (Garg et al., 2019). That is why it is crucial to determine an optimum $\mathrm{Na} / \mathrm{Al}$ ratio needed for AAM mixes to obtain both a high degree of reaction as well as an adequately polymerized structure.

\section{Spatial Phase Mapping via Raman Spectroscopy \& Imaging}

Unlike FTIR or NMR, Raman spectroscopy, so far, has been rarely employed in investigating or describing the structure of the formed gels (Caggiani et al., 2021). Analyzing AAMs using Raman spectroscopy is a quite challenging task because this material exhibits high fluorescence levels when short laser wavelengths are used. Using longer wavelengths can ameliorate the problem; however, it can also result in photoluminescence, probably due to the trace rare earth elements in metakaolin (Torréns-Martín et al., 2013b; Garg et al., 2013; Szechyńska-Hebda et al., 2019). 
A

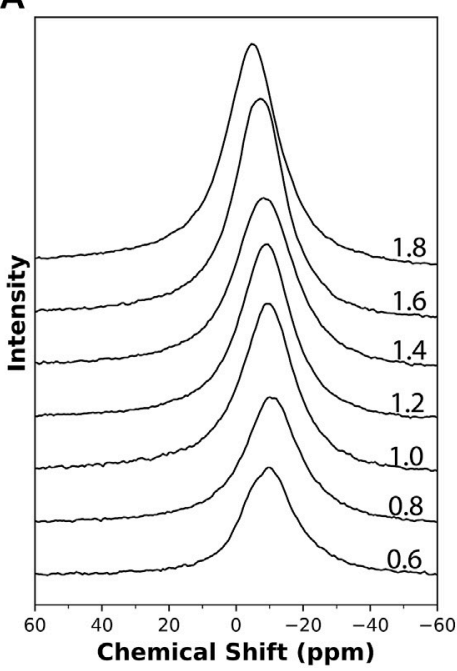

B

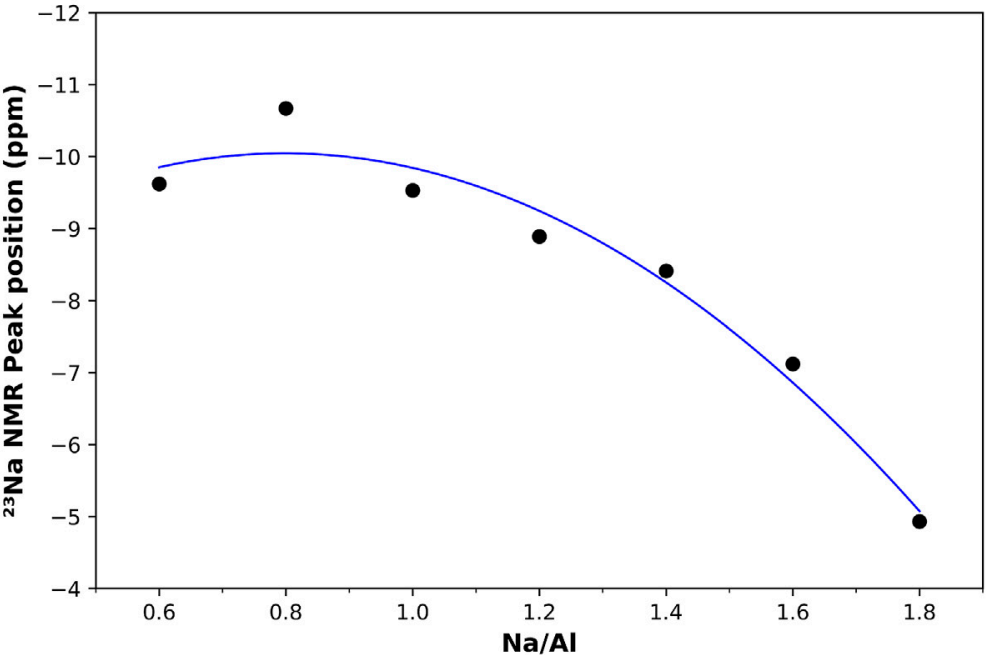

FIGURE 6 | (A) ${ }^{23} \mathrm{Na}$ solid-state MAS NMR results on 4 month old AAM samples with varying Na/Al ratios (0.6-1.8), identified on each plot. (B) The change in the ${ }^{23} \mathrm{Na} \mathrm{NMR}$ peak position with respect to the $\mathrm{Na} / \mathrm{Al}$ ratio.

A

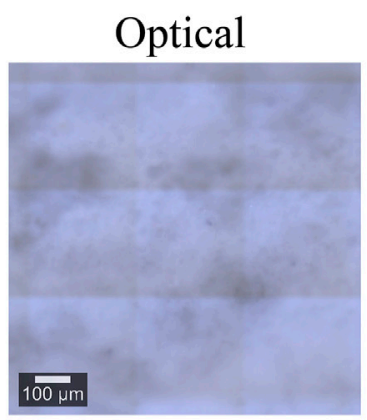

Component 1

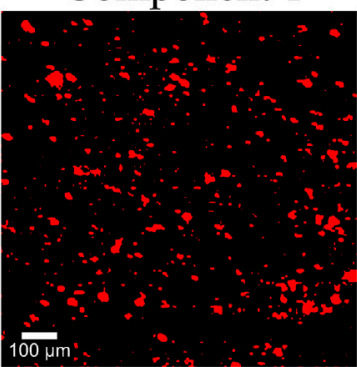

Raman Image

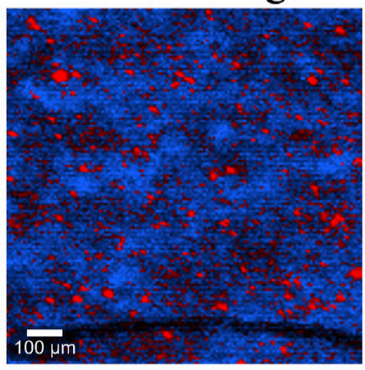

Component 2

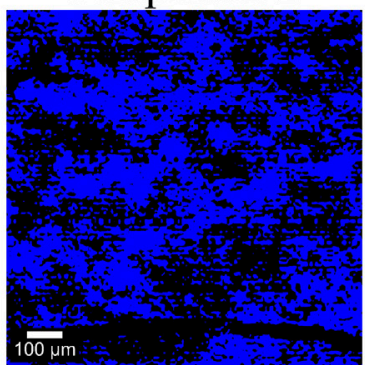

B

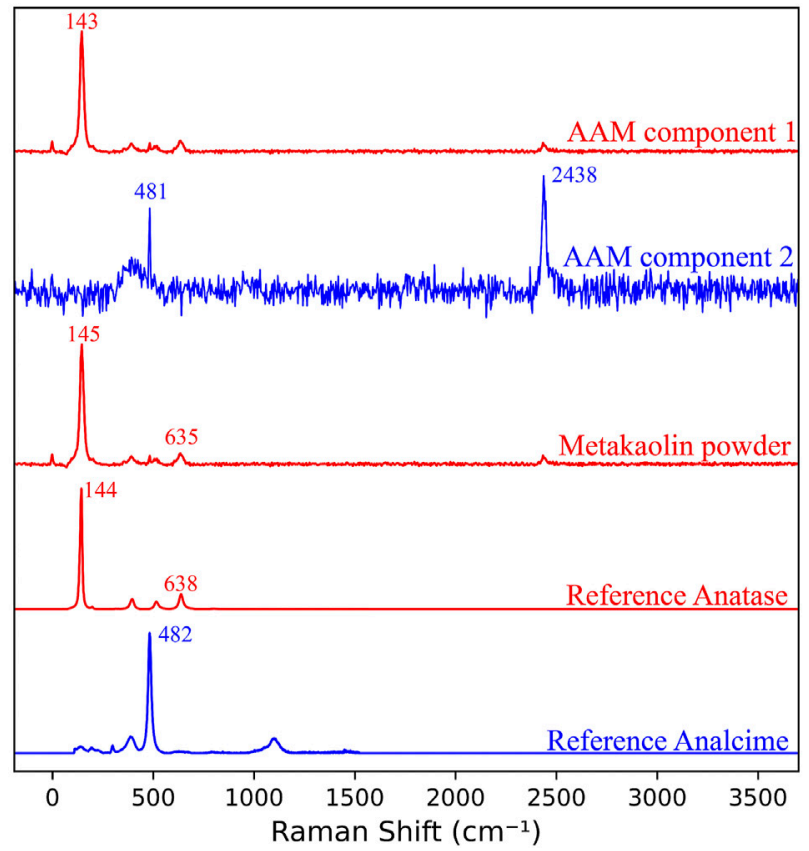

FIGURE 7 | (A) Optical image, combined Raman image, and components maps of a 7 day old AAM sample (B) Raman spectra of AAM's components, raw metakaolin powder, reference Anatase $\left(\mathrm{TiO}_{2}\right)$ (Zhang et al., 2000), and reference Analcime $\left(\mathrm{Na}\left(\mathrm{AlSi}_{2} \mathrm{O}_{6}\right) \cdot \mathrm{H} 2 \mathrm{O}\right)(\mathrm{Presser}$ et al., 2008; Tsai et al., 2021).

Raman spectroscopy and imaging were used in this study with the aim of recognizing the spectrum representing metakaolin and then mapping and quantifying the presence of this spectrum in the AAM scans. Recently, Raman imaging has been instrumental in understanding various complex, heterogeneous systems such as granites (Polavaram and Garg, 2021b), pure cement phases
(Potgieter-Vermaak et al., 2006), phase quantification in anhydrous cements (Polavaram and Garg, 2021a), hydrating cements (Loh et al., 2021), calcium aluminate cements (Black et al., 2006; Torréns-Martín et al., 2013a), and sulfate-attacked cementitious materials (Yue et al., 2013). The purpose of applying Raman spectroscopy and imaging here was to estimate the 
amounts of metakaolin that remained unreacted and thus, estimate the extent of the alkali-activation reaction in mixes with varying alkalinity. A sample of the Raman images and component spectra of a 7 day old AAM sample is shown in Figure 7. Two components were identified in the acquired spectrum. The first component had peaks at 143, 393, and $638 \mathrm{~cm}^{-1}$, while the second one had a peak at around $481 \mathrm{~cm}^{-1}$. The peak present at $2,438 \mathrm{~cm}^{-1}$ was recognized as an artifact in the imaging procedure, potentially attributed to an external light source in the room. The spectrum acquired from scanning metakaolin is shown in Figure $\mathbf{7 B}$, also having the peaks at 143,393 , and $638 \mathrm{~cm}^{-1}$.

When the spectrum obtained from metakaolin was mapped in the scans of activated samples having different $\mathrm{Na} / \mathrm{Al}$ ratios and compared, no recognizable or systematic variance in its amount was observed between the mixes. This does not coincide with the expected decrease in unreacted metakaolin content in the higher alkaline mixes, which means that this spectrum probably does not directly represent metakaolin. That being said, this observation does not rule out future detailed investigations of these systems with Raman imaging where more information can be extracted by optimizing the experimental parameters for these specific samples.

Some previous Raman spectroscopy research done on AAM have attributed the bands at $143,400,514-520$, and $635-640 \mathrm{~cm}^{-1}$ to intratetrahedral vibrations of polymerized silicate tetrahedra, Si-O-T bending, and T-O symmetric stretching modes, respectively (Zhang et al., 2017; Brylewska et al., 2018). However, we believe that these four signals are primarily caused by the anatase present in the raw materials, which has the spectrum shown in Figure 7B (Zhang et al., 2000). This observation was also recognized by other previous researchers (Murad, 1997; Caggiani et al., 2021). In spite of being a minor impurity in metakaolin, the high detection of anatase is due to its exceptionally high cross-section for Raman scattering. This is caused by its molecular transition polarizability and its complex conjugate (Clark et al., 2007; Nakamoto, 2008). Anatase's dominance over the Raman spectra of both metakaolin and the activated AAM constructs a significant draw-back for analyzing these materials using this technique, as it obstructs the ability to observe the other contributions and can lead to misinterpretations (Caggiani et al., 2021). Future investigations will need to focus on highly pure samples as even trace amounts of Anatase can dominate the analytical results.

The second component observed in the AAM spectrum had an observable peak at around $481 \mathrm{~cm}^{-1}$. This peak can be attributed to analcime, one of the species for singly connected four-ring-chain zeolites, having a composition of $\mathrm{NaSi}_{2} \mathrm{AlO}_{6} \cdot \mathrm{H}_{2} \mathrm{O}$ (Tsai et al., 2021). The Raman spectrum of analcime is also shown in Figure 7B (Presser et al., 2008; Tsai et al., 2021). Analcime can be considered a representative for the formed N-A-S-H gel; however, it cannot be mapped as a reference for the amount of formed gel as it is not the only phase formed by the alkali-activation process. Due to the highly amorphous structure of the gel, it was very challenging to detect any other gel phases, leading to difficulty quantifying or comparing the amount of formed gel in the different mixes. Given the challenges noted, efforts need to continue to resolve AAM phases with Raman imaging in future studies. The detection of an analcime type phase via Raman is potentially novel and more efforts could be dedicated in this direction.

\section{DISCUSSION AND BROADER IMPACTS}

By assembling and cross-comparing the data acquired from all the different yet complementary techniques used in this research study, various interesting and novel correlations were found. For instance, the practicality of using FTIR to measure the rate of hydration was evaluated compared to that of isothermal calorimetry. And results acquired from structure-indicating techniques like XRD and NMR were compared to find how well they correlate in identifying the change in structure with changes in $\mathrm{Na} / \mathrm{Al}$ ratio.

Firstly, a correlation between results acquired from isothermal calorimetry and FTIR scanning at two different times $(12 \mathrm{~h}$ and 3 days) is plotted in Figure 8. Interestingly, a direct relationship was found between the cumulative heat of hydration and the position of the peak representing the $\mathrm{Si}-\mathrm{O}-\mathrm{T}$ bonds, where each data point represents a sample with a different $\mathrm{Na} / \mathrm{Al}$ ratio. As the $\mathrm{Na} / \mathrm{Al}$ ratio of the mix increases, the cumulative heat increases, and the location of the peak shifts toward lower wavenumber values. This correlation was tested at two different time points: the first one after $12 \mathrm{~h}$ of activation, shown in Figure $\mathbf{8 A}$, and the other one after 3 days of activation, shown in Figure 8B. Both figures show that the extent of the alkali-activation reaction affects the cumulative heat and the peak position at a similar rate, and the relationship between the two techniques' data is the same even at different time points. This correlation suggests that both techniques can almost equally monitor the amount of reaction at any point in time. This explains why most of the previous research done on AAM has been able to successfully use isothermal calorimetry and FTIR to measure the kinetics of the alkali-activation reaction (Granizo et al., 2002; Provis et al., 2005; Król et al., 2019).

TGA is another technique that was used to track the degree of reaction for each mix. Previous researchers have used it along with isothermal calorimetry to measure the extent of hydration of cementitious materials (Pane and Hansen, 2005; Deboucha et al., 2017). And since this degree of reaction can be represented by both techniques, a possible correlation between TGA's and the isothermal calorimetry's data was investigated and plotted in Figure 9. Again, we observe a close relationship between TGA's weight loss percentage at a temperature of $400^{\circ} \mathrm{C}$ for 3 month old samples and the cumulative heat obtained by isothermal calorimetry after 3 days of alkali-activation. The correlation between both measurements indicated a strong equivalence between both techniques as they have almost identical sensitivity to the $\mathrm{Na} / \mathrm{Al}$ ratio variation. Although isothermal calorimetry is considered the most reliable method to measure the degree of the activation reaction, it requires monitoring the samples in the first $45 \mathrm{~h}$ after hydration. Based on this correlation, it is possible to also use TGA to provide a close estimation for the extent of hydration for the already activated and hardened mixes.

On the other hand, changes in the structure of the activation products were monitored by both NMR (on 4 month old samples) and XRD (3 month old samples). In ${ }^{27} \mathrm{Al} \mathrm{NMR}$, the position of the 

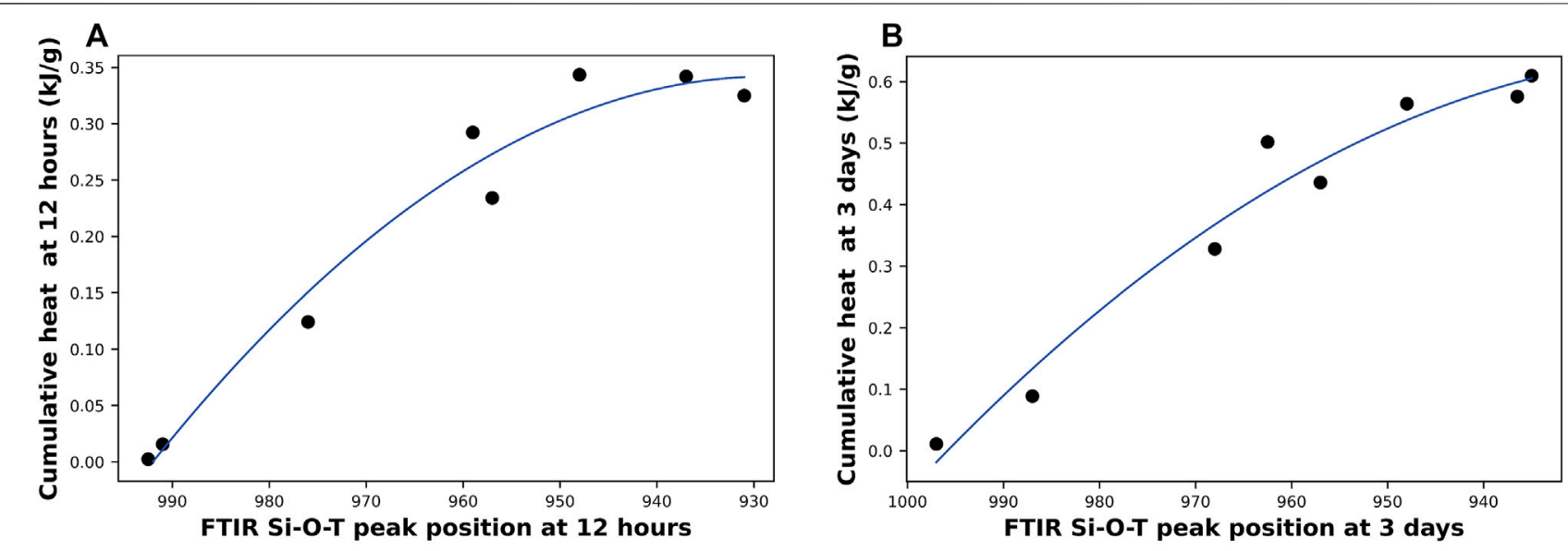

FIGURE 8 | A correlation between the total heat generated from isothermal calorimetry and the position of the Si-O-T peak from FTIR scans after (A) $12 \mathrm{~h}$ of hydration and (B) 3 days of hydration. Each data point represents a different Na/Al ratio (0.6-1.8).

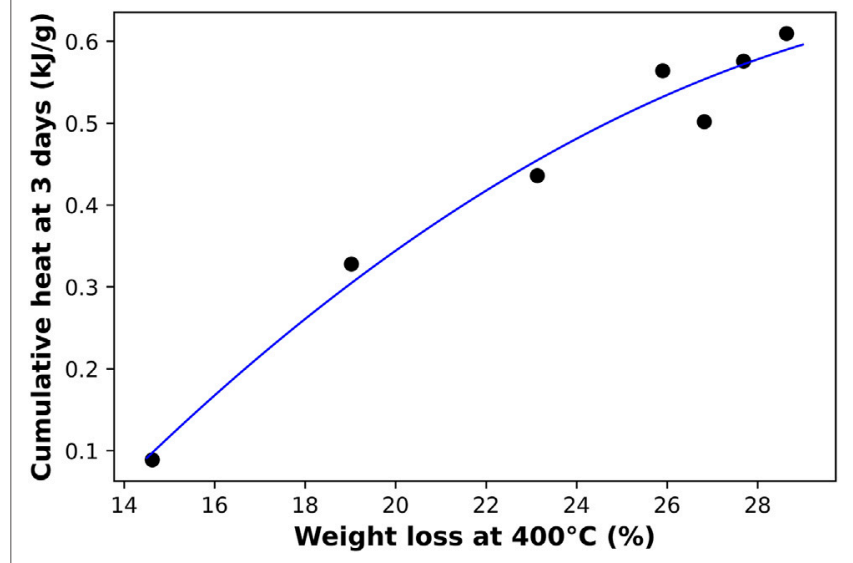

FIGURE 9 | A correlation between the weight loss percentage acquired from TGA tests at $400^{\circ} \mathrm{C}$ on 3 month old AAM samples and the cumulative heat obtained by isothermal calorimetry after 3 days of reaction. Each data point represents a different $\mathrm{Na} / \mathrm{Al}$ ratio $(0.6-1.8)$.

resonance peak representing the $\mathrm{Al}^{(4)}$ coordination was observed to be shifting towards higher frequency with the increase in $\mathrm{Na} / \mathrm{Al}$ ratio, potentially indicating less shielded $\mathrm{Al}$ sites in the $\mathrm{N}$-A-S-H gel structure (Zeng et al., 2000). As for XRD, the centroid of the zeolite peak was also found to be shifting towards higher $2 \theta$ values and away from the original hump observed in the metakaolin precursor. The rates of shifts in these peaks represent the rate of change in binder structure with respect to the $\mathrm{Na} / \mathrm{Al}$ ratio. A correlation between the peaks positions of NMR's $\mathrm{Al}^{(4)}$ coordination and XRD's zeolite is plotted in Figure 10A. This plot shows the similarity in the rate of structure change identified by both techniques, particularly the considerable leap that occurred in the binder structure between $\mathrm{Na} / \mathrm{Al}$ ratios of 0.6 and 0.8 . This leap was almost equally recognized by both techniques.

Another way to indicate the extent of a reaction is by comparing a parameter that resembles the reaction product with another constant or less affected one. This method was applied both in XRD and NMR. In XRD, the increase in alkaliactivation reaction results in an increase of zeolite and/or N-A-S$\mathrm{H}$ gel formation, causing its hump to increase in size (Provis et al., 2005), while the other distinctive peak, representing anatase, remains constant, as it is not involved in any chemical reactions. Thus, a ratio of zeolite peak height to that of anatase can indicate the extent of reaction that took place in each mix. As for NMR, the reaction leads to the transformation of $\mathrm{Al}^{(5)}$ and $\mathrm{Al}^{(6)}$ coordination environments into $\mathrm{Al}^{(4)}$, so a higher degree of reaction should result in a lower ratio of $\left(\mathrm{Al}^{(5)}+\mathrm{Al}^{(6)}\right)$ / $\mathrm{Al}^{(4)}$. That is why this ratio can be considered a representative of the unreacted metakaolin, and so, another indication of the extent of the alkali-activation reaction. These two ratios from both techniques are plotted together in Figure 10B. It is observed that although both ratios have a clear trend with $\mathrm{Na} / \mathrm{Al}$ ratio, the rate of change of both ratios is slightly different. Both ratios are still pretty successful in indicating the extent of alkali-activation with the change in the $\mathrm{Na} / \mathrm{Al}$ ratio. Overall, these widely different techniques are found to heavily complement each other in unambiguously finding evidence for a higher extent of alkaliactivation reaction with increasing $\mathrm{Na} / \mathrm{Al}$ ratio. However, the relationship between extent of reaction and $\mathrm{Na} / \mathrm{Al}$ ratio is not perfectly linear and instead shows a parabolic behavior with diminishing returns. That is, at very high $\mathrm{Na} / \mathrm{Al}$ ratios the reactants and products reach a saturation stage where the increase extent of reaction is not linearly proportional to the increase in $\mathrm{Na} / \mathrm{Al}$ ratio, suggesting a practical upper limit to the alkalinity of the activator to be used for commercial applications.

The ${ }^{23} \mathrm{Na}$ NMR results showed a shifting peak position towards more positive chemical shift values with the increase in $\mathrm{Na} / \mathrm{Al}$ ratios, indicating more $\mathrm{NBO} / \mathrm{T}$ in the structure and a potentially less polymerized gel structure. It is also observed in Figure 6B that these shifts are not noticeable for low $\mathrm{Na} / \mathrm{Al}$ ratios, and they get more significant at the upper range of $\mathrm{Na} / \mathrm{Al}$ ratios. These results also demonstrate the diminishing returns for high $\mathrm{Na} / \mathrm{Al}$ ratios in AAMs. 

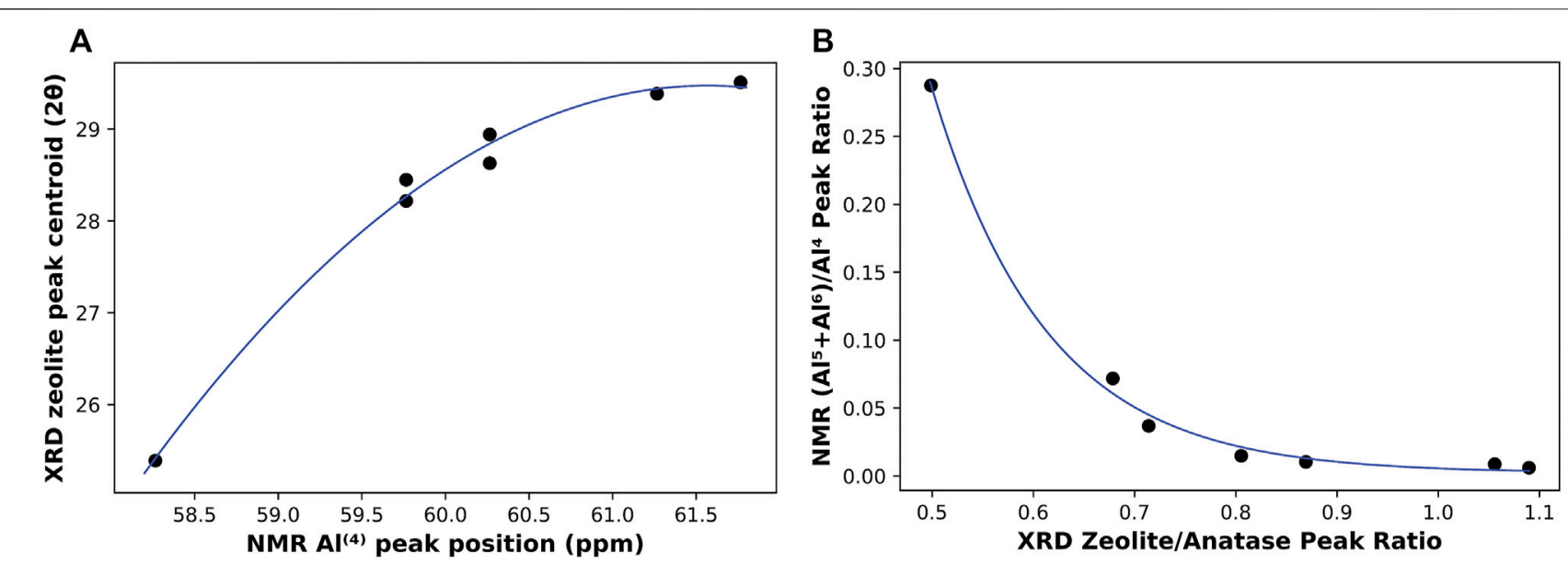

FIGURE 10 | A correlation between NMR (4 month old samples) and XRD (3 month old samples) results. (A) shows the relationship between Al ${ }^{(4)}$ peak position $(\mathrm{ppm})$ referenced to $\mathrm{Al}\left(\mathrm{NO}_{3}\right)_{3}$ solution and XRD centroid of zeolite hump $(2 \theta)$, and $(\mathbf{B})$ shows the ratio of $\mathrm{NMR}^{\prime} \mathrm{s}\left(\mathrm{Al}{ }^{(5)}+\mathrm{Al}{ }^{(6)}\right) / \mathrm{Al}{ }^{(4)}$ compared to the ratio of zeolite/anatase peaks from $X R D$.

\section{CONCLUSION}

A multi-technique investigation was performed in this study on alkali-activated metakaolin mixes to investigate the effect of $\mathrm{Na}$ / $\mathrm{Al}$ ratio on the alkali-activation reaction kinetics and the final phase assemblage using a wide range of $\mathrm{Na} / \mathrm{Al}$ ratios of $0.5-1.8$. The reaction kinetics were studied using isothermal calorimetry, FTIR, and TGA. The isothermal calorimetry tests indicated higher heat flow and cumulative heat for higher alkalinity mixes, ranging from $0.01 \mathrm{~kJ} / \mathrm{g}$ to $0.69 \mathrm{~kJ} / \mathrm{g}$ for $\mathrm{Na} / \mathrm{Al}$ ratios of 0.5 and 1.8 , respectively. This increase in cumulative heat indicates a higher rate and extent of activation reaction for higher $\mathrm{Na} / \mathrm{Al}$ ratio mixes. This result was also supported by the negative shift of the Si-O-T band in the AAM samples' FTIR spectra. The Si-O-T band position shifted from $997 \mathrm{~cm}^{-1}$ for $\mathrm{Na} / \mathrm{Al}$ of $0.5-935 \mathrm{~cm}^{-1}$ for $\mathrm{Na} / \mathrm{Al}$ ratio of 1.8 , indicating lower amounts of unreacted metakaolin in the high alkalinity mixes. Finally, TGA results on 3 month old AAM samples showed an increasing weight loss percentage, from 14.6 to $28.6 \%$, by increasing the $\mathrm{Na} / \mathrm{Al}$ ratio from 0.6 to 1.8 , which confirmed the increase in the amount of the N-A-S-H gel inside the samples.

The phase assemblage in these AAM samples was also analyzed using XRD, NMR, and Raman spectroscopy and imaging. The increase in the $\mathrm{Na} / \mathrm{Al}$ ratio resulted in an increasing peak-sharpening in addition to a position shift of the zeolite hump at $2 \theta$ range of $27-29^{\circ}$, with the hump's centroid shifting from $25.4^{\circ} 2 \theta$ to $29.5^{\circ}$ in the XRD diffractogram. This observation was an indication of the greater extent of the alkali-activation process of metakaolin. Similarly, the ratio of the peak heights of $\mathrm{Al}^{(5)}$ and $\mathrm{Al}^{(6)}$ to $\mathrm{Al}^{(4)}$ coordination in ${ }^{27} \mathrm{Al}$ MAS NMR was found to be decreasing from 0.28 to 0.006 for $\mathrm{Na} / \mathrm{Al}$ ratio of 0.6 and 1.8 , respectively. That is in addition to the shift in $\mathrm{Al}^{(4)}$ peak position from $58.2 \mathrm{ppm}$ to $61.8 \mathrm{ppm}$. These results indicated the lower amounts of unreacted metakaolin that are present in high $\mathrm{Na}$ / Al mixes.
The position of the peak obtained from ${ }^{23} \mathrm{Na}$ MAS NMR scans was found to be shifting towards more positive chemical shift values with increasing the $\mathrm{Na} / \mathrm{Al}$, indicating a higher $\mathrm{NBO} / \mathrm{T}$ and a potentially lower degree of polymerization of the gel structure.

Lastly, the use of Raman spectroscopy and imaging to track the alkali-activation process of metakaolin was found to be challenging due to the highly amorphous product gel. However, our Raman data revealed that some of the peaks previously attributed to reaction products likely belong to a trace yet common Anatase impurity in the precursor metakaolin. Moreover, a unique analcime like structure was detected via Raman which warrants further investigation.

Finally, comparison of data obtained from all the techniques employed here showed a clear, non-linear relationship between extent of alkali-activation reaction and $\mathrm{Na} / \mathrm{Al}$ ratio suggesting diminishing returns at higher ratios. Correlations have also been found between the results of the different techniques used. The results showed a strong correlation between the cumulative heat obtained from isothermal calorimetry and the position shift of the Si-O-T band observed by FTIR. Another strong positive correlation was found between the cumulative heat and the total weight loss of the AAM obtained by TGA. In addition, the results of XRD and NMR both showed clear comparable trend with $\mathrm{Na} / \mathrm{Al}$ ratio. This was deduced by comparing the shifts of ${ }^{27} \mathrm{Al}$ NMR's $\mathrm{Al}^{(4)}$ coordination's peak position and XRD's zeolite peak position, as well as the ratios of XRD's zeolite/anatase and ${ }^{27} \mathrm{Al}$ NMR's $\left(\mathrm{Al}^{(5)}+\mathrm{Al}^{(6)} / \mathrm{Al}^{(4)}\right)$. These findings could guide commercial applications where alkalinity of the activator is an important parameter for performance as well as safety.

\section{DATA AVAILABILITY STATEMENT}

The original contributions presented in the study are included in the article/supplementary material, further inquiries can be directed to the corresponding author. 


\section{AUTHOR CONTRIBUTIONS}

OA conducted the experiments. OA and NG analyzed the data, prepared the figures, and wrote the manuscript. NG acquired funding, and supervised the study.

\section{FUNDING}

The authors acknowledge the Department of Civil and Environmental Engineering at the University of Illinois at Urbana-Champaign for supporting this work.

\section{REFERENCES}

Abdalqader, A. F., Jin, F., and Al-Tabbaa, A. (2015). Characterisation of Reactive Magnesia and Sodium Carbonate-Activated Fly Ash/slag Paste Blends. Construction Building Mater. 93, 506-513. doi:10.1016/ j.conbuildmat.2015.06.015

Alonso, S., and Palomo, A. (2001). Alkaline Activation of Metakaolin and Calcium Hydroxide Mixtures: Influence of Temperature, Activator Concentration and Solids Ratio. Mater. Lett. 47, 55-62. doi:10.1016/S0167-577X(00)00212-3

Alventosa, K. M. L., and White, C. E. (2021). The Effects of Calcium Hydroxide and Activator Chemistry on Alkali-Activated Metakaolin Pastes. Cement Concrete Res. 145, 106453. doi:10.1016/j.cemconres.2021.106453

Alzeer, M. I. M., Nguyen, H., Cheeseman, C., and Kinnunen, P. (2021). AlkaliActivation of Synthetic Aluminosilicate Glass with Basaltic Composition. Front. Chem. 9, 706. doi:10.3389/fchem.2021.715052

Balzer, R., Behrens, H., Waurischk, T., Reinsch, S., Müller, R., Kiefer, P., et al. (2020). Water in Alkali Aluminosilicate Glasses. Front. Mater. 7, 85. doi:10.3389/fmats.2020.00085

Barbosa, V. F. F., MacKenzie, K. J. D., and Thaumaturgo, C. (2000). Synthesis and Characterisation of Materials Based on Inorganic Polymers of Alumina and Silica: Sodium Polysialate Polymers. Int. J. Inorg. Mater. 2, 309-317. doi:10.1016/S1466-6049(00)00041-6

Biel, O., Rożek, P., Florek, P., Mozgawa, W., and Król, M. (2020). Alkaline Activation of Kaolin Group Minerals. Crystals 10, 268. doi:10.3390/ cryst10040268

Black, L., Breen, C., Yarwood, J., Deng, C.-S., Phipps, J., and Maitland, G. (2006). Hydration of Tricalcium Aluminate (C3A) in the Presence and Absence of gypsum-studied by Raman Spectroscopy and X-ray Diffraction. J. Mater. Chem. 16, 1263-1272. doi:10.1039/b509904h

Brylewska, K., Rożek, P., Król, M., and Mozgawa, W. (2018). The Influence of Dealumination/desilication on Structural Properties of Metakaolin-Based Geopolymers. Ceramics Int. 44, 12853-12861. doi:10.1016/ j.ceramint.2018.04.095

Caggiani, M. C., Coccato, A., Barone, G., Finocchiaro, C., Fugazzotto, M., Lanzafame, G., et al. (2021). Raman Spectroscopy Potentiality in the Study of Geopolymers Reaction Degree. J. Raman Spectrosc. 1, 0377-0486. doi:10.1002/jrs.6167

Chaipanich, A., Wianglor, K., Piyaworapaiboon, M., and Sinthupinyo, S. (2019). Thermogravimetric Analysis and Microstructure of Alkali-Activated Metakaolin Cement Pastes. J. Therm. Anal. Calorim. 138, 1965-1970. doi:10.1007/s10973-019-08592-z

Clark, R. J. H., Wang, Q., and Correia, A. (2007). Can the Raman Spectrum of Anatase in Artwork and Archaeology Be Used for Dating Purposes? Identification by Raman Microscopy of Anatase in Decorative Coatings on Neolithic (Yangshao) Pottery from Henan, China. J. Archaeological Sci. 34, 1787-1793. doi:10.1016/j.jas.2006.12.018

Davidovits, J. (1989). Geopolymers and Geopolymeric Materials. J. Therm. Anal. 35, 429-441. doi:10.1007/BF01904446

Davidovits, J. (1988). "Structural Characterization of Geopolymeric Materials with X-Ray Diffractometry and MAS-NMR Spectroscopy," in Geopolymer 1988 (Compeigne, France: Universite de Technologie de Compeigne), 149-166.

\section{ACKNOWLEDGMENTS}

The authors acknowledge BASF for kindly supporting metakaolin used in the study. The authors also thank PQ corporation for supplying the sodium silicate solution. The authors acknowledge Andre Sutrisno and the NMR laboratory at the School of Chemical Sciences at the University of Illinois at UrbanaChampaign for assisting with the NMR experiments. This research was carried out in part at the Materials Research Laboratory (MRL) Central Research Facilities at UIUC. Raman spectroscopy and imaging were done at the Core Facilities at the Carl R. Woese Institute of Genomic Biology at UIUC.

De Vargas, A. S., Dal Molin, D. C. C., Vilela, A. C. F., Silva, F. J. d., Pavão, B., and Veit, H. (2011). The Effects of $\mathrm{Na} 2 \mathrm{O} / \mathrm{SiO} 2$ molar Ratio, Curing Temperature and Age on Compressive Strength, Morphology and Microstructure of AlkaliActivated Fly Ash-Based Geopolymers. Cement and Concrete Composites 33, 653-660. doi:10.1016/j.cemconcomp.2011.03.006

Deboucha, W., Leklou, N., Khelidj, A., and Oudjit, M. N. (2017). Hydration Development of mineral Additives Blended Cement Using Thermogravimetric Analysis (TGA): Methodology of Calculating the Degree of Hydration. Construction Building Mater. 146, 687-701. doi:10.1016/j.conbuildmat.2017.04.132

Duxson, P., Lukey, G. C., Separovic, F., and Van Deventer, J. S. J. (2005). Effect of Alkali Cations on Aluminum Incorporation in Geopolymeric Gels. Ind. Eng. Chem. Res. 44, 832-839. doi:10.1021/ie0494216

Duxson, P., Fernández-Jiménez, A., Provis, J. L., Lukey, G. C., Palomo, A., and Van Deventer, J. S. J. (2007a). Geopolymer Technology: The Current State of the Art. J. Mater. Sci. 42, 2917-2933. doi:10.1007/s10853-006-0637-z

Duxson, P., Lukey, G. C., and Van Deventer, J. S. J. (2007b). Physical Evolution of Na-Geopolymer Derived from Metakaolin up to $1000{ }^{\circ}$ C. J. Mater. Sci. 42, 3044-3054. doi:10.1007/s10853-006-0535-4

Escalante-García, J. I., Fuentes, A. F., Gorokhovsky, A., Fraire-Luna, P. E., and Mendoza-Suarez, G. (2003). Hydration Products and Reactivity of BlastFurnace Slag Activated by Various Alkalis. J. Am. Ceram. Soc. 86, 2148-2153. doi:10.1111/j.1151-2916.2003.tb03623.x

Fernandez, R., Martirena, F., and Scrivener, K. L. (2011). The Origin of the Pozzolanic Activity of Calcined clay Minerals: A Comparison between Kaolinite, Illite and Montmorillonite. Cement Concrete Res. 41, 113-122. doi:10.1016/j.cemconres.2010.09.013

Fernández-Jiménez, A., Puertas, F., Sobrados, I., and Sanz, J. (2003). Structure of Calcium Silicate Hydrates Formed in Alkaline-Activated Slag: Influence of the Type of Alkaline Activator. J. Am. Ceram. Soc. 86, 1389-1394. doi:10.1111/ j.1151-2916.2003.tb03481.x

Garg, N., Özçelik, V. O., Skibsted, J., and White, C. E. (2019). Nanoscale Ordering and Depolymerization of Calcium Silicate Hydrates in the Presence of Alkalis. J. Phys. Chem. C. 123, 24873-24883. doi:10.1021/ acs.jpcc.9b06412

Garg, N., and Skibsted, J. (2019). Dissolution Kinetics of Calcined Kaolinite and Montmorillonite in Alkaline Conditions: Evidence for Reactive $\mathrm{Al}(\mathrm{V})$ Sites. J. Am. Ceram. Soc. 102, 7720-7734. doi:10.1111/jace.16663

Garg, N., Wang, K., and Martin, S. W. (2013). A Raman Spectroscopic Study of the Evolution of Sulfates and Hydroxides in Cement-Fly Ash Pastes. Cement Concrete Res. 53, 91-103. doi:10.1016/j.cemconres.2013.06.009

Garg, N., and White, C. E. (2017). Mechanism of Zinc Oxide Retardation in AlkaliActivated Materials: an In Situ X-ray Pair Distribution Function Investigation. J. Mater. Chem. A. 5, 11794-11804. doi:10.1039/c7ta00412e

Gartner, E. (2004). Industrially Interesting Approaches to "low-CO2" Cements. Cement Concrete Res. 34, 1489-1498. doi:10.1016/j.cemconres.2004.01.021

Ghanbari, M., Hadian, A. M., Nourbakhsh, A. A., and MacKenzie, K. J. D. (2017). Modeling and Optimization of Compressive Strength and Bulk Density of Metakaolin-Based Geopolymer Using central Composite Design: A Numerical and Experimental Study. Ceramics Int. 43, 324-335. doi:10.1016/ j.ceramint.2016.09.159

Gong, K., Cheng, Y., Daemen, L. L., and White, C. E. (2019). In Situ quasi-elastic Neutron Scattering Study on the Water Dynamics and Reaction Mechanisms in 
Alkali-Activated Slags. Phys. Chem. Chem. Phys. 21, 10277-10292. doi:10.1039/ c9cp00889f

Granizo, M. L., Alonso, S., Blanco-Varela, M. T., and Palomo, A. (2002). Alkaline Activation of Metakaolin: Effect of Calcium Hydroxide in the Products of Reaction. J. Am. Ceram. Soc. 85, 225-231. doi:10.1111/j.11512916.2002.tb00070.x

Granizo, M. L., and Blanco, M. T. (1998). Alkaline Activation of Metakaolin: An Isothermal Conduction Calorimetry Study. J. Therm. Anal. Calorim. 52, 957-965. doi:10.1023/A:1010176321136

Granizo, M. L., Blanco-Varela, M. T., and Palomo, A. (2000). Influence of the Starting Kaolin on Alkali-Activated Materials Based on Metakaolin. Study of the Reaction Parameters by Isothermal Conduction Calorimetry. J. Mater. Sci. 35, 6309-6315. doi:10.1023/A:1026790924882

Granizo, N., Palomo, A., and Fernandez-Jiménez, A. (2014). Effect of Temperature and Alkaline Concentration on Metakaolin Leaching Kinetics. Ceramics Int. 40, 8975-8985. doi:10.1016/j.ceramint.2014.02.071

Hou, L., Li, J., and Luyuan, Z.-y. (2019). Effect of Na/Al on Formation, Structures and Properties of Metakaolin Based Na-Geopolymer. Construction Building Mater. 226, 250-258. doi:10.1016/j.conbuildmat.2019.07.171

Howard, C. J., Sabine, T. M., and Dickson, F. (1991). Structural and thermal Parameters for Rutile and Anatase. Acta Crystallogr. Sect. B. 47, 462-468. doi:10.1107/S010876819100335X

Khale, D., and Chaudhary, R. (2007). Mechanism of Geopolymerization and Factors Influencing its Development: A Review. J. Mater. Sci. 42, 729-746. doi:10.1007/s10853-006-0401-4

Kragten, D. D., Fedeyko, J. M., Sawant, K. R., Rimer, J. D., Vlachos, D. G., Lobo, R. F., et al. (2003). Structure of the Silica Phase Extracted from silica/(TPA)OH Solutions Containing Nanoparticles. J. Phys. Chem. B. 107, 10006-10016. doi:10.1021/jp035110h

Krivenko, P. V. (1994). "Alkaline Cements," in Proceedings of the First International Conference (Kiev, Ukraine: VIPOL Stock Company), 11-129. Available at: http://ci.nii.ac.jp/naid/10027275971/en/ (Accessed September 5, 2021).

Król, M., Minkiewicz, J., and Mozgawa, W. (2016). IR Spectroscopy Studies of Zeolites in Geopolymeric Materials Derived from Kaolinite. J. Mol. Struct. 1126, 200-206. doi:10.1016/j.molstruc.2016.02.027

Król, M., Mozgawa, W., Jastrzębski, W., and Barczyk, K. (2012). Application of IR Spectra in the Studies of Zeolites from D4R and D6R Structural Groups. Microporous Mesoporous Mater. 156, 181-188. doi:10.1016/ j.micromeso.2012.02.040

Król, M., Rożek, P., Chlebda, D., and Mozgawa, W. (2019). ATR/FT-IR Studies of Zeolite Formation during Alkali-Activation of Metakaolin. Solid State. Sci. 94, 114-119. doi:10.1016/j.solidstatesciences.2019.06.004

Li, Z., Zhang, S., Zuo, Y., Chen, W., and Ye, G. (2019). Chemical Deformation of Metakaolin Based Geopolymer. Cement Concrete Res. 120, 108-118. doi:10.1016/j.cemconres.2019.03.017

Loewenstein, W. (1954). The Distribution of Aluminum in the Tetrahedra of Silicates and Aluminates. Am. Mineral. 39, 92-96.

Loh, H.-C., Kim, H.-J., Ulm, F.-J., and Masic, A. (2021). Time-Space-Resolved Chemical Deconvolution of Cementitious Colloidal Systems Using Raman Spectroscopy. Langmuir 37, 7019-7031. doi:10.1021/acs.langmuir.1c00609

Mozgawa, W. (2001). The Relation between Structure and Vibrational Spectra of Natural Zeolites. J. Mol. Struct. 596, 129-137. Elsevier. doi:10.1016/ S0022-2860(01)00741-4

Murad, E. (1997). Identification of Minor Amounts of Anatase in Kaolins by Raman Spectroscopy. Am. Mineral. 82, 203-206. doi:10.2138/am-1997$1-222$

Myers, R. J., Bernal, S. A., San Nicolas, R., and Provis, J. L. (2013). Generalized Structural Description of Calcium-Sodium Aluminosilicate Hydrate Gels: The Cross-Linked Substituted Tobermorite Model. Langmuir 29, 5294-5306. doi:10.1021/la4000473

Nakamoto, K. (2008). Infrared and Raman Spectra of Inorganic and Coordination Compounds: Part A: Theory and Applications in Inorganic Chemistry. 6th ed. New Jersey: John Wiley \& Sons. doi:10.1002/ 9780470405840

Nath, S. K., Maitra, S., Mukherjee, S., and Kumar, S. (2016). Microstructural and Morphological Evolution of Fly Ash Based Geopolymers. Construction Building Mater. 111, 758-765. doi:10.1016/j.conbuildmat.2016.02.106
Nikolakis, V., Kokkoli, E., Tirrell, M., Tsapatsis, M., and Vlachos, D. G. (2000). Zeolite Growth by Addition of Subcolloidal Particles: Modeling and Experimental Validation. Chem. Mater. 12, 845-853. doi:10.1021/cm990653i

Palomo, A., and López dela Fuente, J. I. (2003). Alkali-activated Cementitous Materials: Alternative Matrices for the Immobilisation of Hazardous Wastes. Cement Concrete Res. 33, 281-288. doi:10.1016/S0008-8846(02)00963-8

Palomo, A., Maltseva, O., Garcia-Lodeiro, I., and Fernández-Jiménez, A. (2021). Portland versus Alkaline Cement: Continuity or Clean Break: "A Key Decision for Global Sustainability". Front. Chem. 9, 653. doi:10.3389/fchem.2021.705475

Pane, I., and Hansen, W. (2005). Investigation of Blended Cement Hydration by Isothermal Calorimetry and thermal Analysis. Cement Concrete Res. 35, 1155-1164. doi:10.1016/j.cemconres.2004.10.027

Polavaram, K. C., and Garg, N. (2021a). Enabling Phase Quantification of Anhydrous Cements via Raman Imaging. Cement Concrete Res. 150, 106592. doi:10.1016/J.CEMCONRES.2021.106592

Polavaram, K. C., and Garg, N. (2021b). High-fidelity and High-Resolution Phase Mapping of Granites via Confocal Raman Imaging. Sci. Rep. 11, 1-10. doi:10.1038/s41598-021-87488-1

Potgieter-Vermaak, S. S., Potgieter, J. H., and Van Grieken, R. (2006). The Application of Raman Spectrometry to Investigate and Characterize Cement, Part I: A Review. Cement Concrete Res. 36, 656-662. doi:10.1016/ j.cemconres.2005.09.008

Presser, V., Kloužková, A., Mrázová, M., Kohoutková, M., and Berthold, C. (2008). Micro-Raman Spectroscopy on Analcime and Pollucite in Comparison to X-ray Diffraction. J. Raman Spectrosc. 39, 587-592. doi:10.1002/jrs.1886

Provis, J., and Deventer, J. V. (2009). Geopolymers: Structures, Processing, Properties and Industrial Applications. Cambridge, UK: Woodhead Publishing. Available at: https://www.sciencedirect.com/science/article/ pii/B9781845694494500011 (Accessed October 3, 2021).

Provis, J. L., Lukey, G. C., and Van Deventer, J. S. J. (2005). Do geopolymers Actually Contain Nanocrystalline Zeolites? a Reexamination of Existing Results. Chem. Mater. 17, 3075-3085. doi:10.1021/cm050230i

Rees, C. A., Provis, J. L., Lukey, G. C., and Van Deventer, J. S. J. (2007). In Situ ATR-FTIR Study of the Early Stages of Fly Ash Geopolymer Gel Formation. Langmuir 23, 9076-9082. doi:10.1021/la701185g

Rivera, J., Castro, F., Fernández-Jiménez, A., and Cristelo, N. (2021). AlkaliActivated Cements from Urban, Mining and Agro-Industrial Waste: StateOf-The-Art and Opportunities. Waste Biomass Valor. 12, 2665-2683. doi:10.1007/s12649-020-01071-9

Rocha, J. (1999). Single- and Triple-Quantum 27Al MAS NMR Study of the Thermal Transformation of Kaolinite. J. Phys. Chem. B 103, 9801-9804. doi:10.1021/jp991516b

Rocha, T., Dias, D., França, F., Guerra, R., and Marques, L. R. d. C. d. O. (2018). Metakaolin-based Geopolymer Mortars with Different Alkaline Activators $(\mathrm{Na}+$ and $\mathrm{K}+$ ). Construction Building Mater. 178, 453-461. doi:10.1016/ j.conbuildmat.2018.05.172

Rowles, M., and O'Connor, B. (2003). Chemical Optimisation of the Compressive Strength of Aluminosilicate Geopolymers Synthesised by Sodium Silicate Activation of Metakaolinite. J. Mater. Chem. 13, 1161-1165. doi:10.1039/b212629j

Rowles, M. R., Hanna, J. V., Pike, K. J., Smith, M. E., and O'Connor, B. H. (2007). 29Si, 27 Al, $1 \mathrm{H}$ and $23 \mathrm{Na}$ MAS NMR Study of the Bonding Character in Aluminosilicate Inorganic Polymers. Appl. Magn. Reson. 32, 663-689. doi:10.1007/s00723-007-0043-y

Ruiz-Santaquiteria, C., Fernández-Jiménez, A., Skibsted, J., and Palomo, A. (2013). Clay Reactivity: Production of Alkali Activated Cements. Appl. Clay Sci. 73, 11-16. doi:10.1016/j.clay.2012.10.012

Ruiz-Santaquiteria, C., Skibsted, J., Fernández-Jiménez, A., and Palomo, A. (2012). Alkaline Solution/binder Ratio as a Determining Factor in the Alkaline Activation of Aluminosilicates. Cement Concrete Res. 42, 1242-1251. doi:10.1016/j.cemconres.2012.05.019

Sankar, K., Sutrisno, A., and Kriven, W. M. (2019). Slag-fly Ash and Slagmetakaolin Binders: Part II -Properties of Precursors and NMR Study of Poorly Ordered Phases. J. Am. Ceram. Soc. 102, 3204-3227. doi:10.1111/ jace. 16224

Silva, P. D., Sagoe-Crenstil, K., and Sirivivatnanon, V. (2007). Kinetics of Geopolymerization: Role of $\mathrm{Al} 2 \mathrm{O} 3$ and $\mathrm{SiO} 2$. Cement Concrete Res. 37, 512-518. doi:10.1016/j.cemconres.2007.01.003 
Singh, P. S., Bastow, T., and Trigg, M. (2005). Structural Studies of Geopolymers by $29 \mathrm{Si}$ and 27Al MAS-NMR. J. Mater. Sci. 40, 3951-3961. doi:10.1007/s10853-005-1915-x

Škvára, F., Kopecký, L., Šmilauer, V., and Bittnar, Z. (2009). Material and Structural Characterization of Alkali Activated Low-Calcium Brown Coal Fly Ash. J. Hazard. Mater. 168, 711-720. doi:10.1016/ j.jhazmat.2009.02.089

Stubican, V., and Roy, R. (1961). Infrared Spectra of Layer-Structure Silicates. J. Am. Ceram. Soc. 44, 625-627. doi:10.1111/j.1151-2916.1961.tb11670.x

Sun, Z., and Vollpracht, A. (2018). Isothermal Calorimetry and In-Situ XRD Study of the $\mathrm{NaOH}$ Activated Fly Ash, Metakaolin and Slag. Cement Concrete Res. 103, 110-122. doi:10.1016/j.cemconres.2017.10.004

Szechyńska-Hebda, M., Marczyk, J., Ziejewska, C., Hordyńska, N., Mikuła, J., and Hebda, M. (2019). Neutral Geopolymer Foams Reinforced with Cellulose Studied with the FT-Raman Spectroscopy. IOP Conf. Ser. Mater. Sci. Eng. 706, 012017. doi:10.1088/1757-899X/706/1/012017

Thamaphat, K., Limsuwan, P., and Ngotawornchai, B. (2008). Phase Characterization of TiO2 Powder by XRD and TEM. Kasetsart J.(Nat. Sci. 42, 357-361. Available at: https://li01.tci-thaijo.org/index.php/anres/ article/view/244620 (Accessed September 20, 2021).

Torréns-Martín, D., Fernández-Carrasco, L., and Martínez-Ramírez, S. (2013a). Hydration of Calcium Aluminates and Calcium Sulfoaluminate Studied by Raman Spectroscopy. Cement Concrete Res. 47, 43-50. doi:10.1016/j.cemconres.2013.01.015

Torréns-Martín, D., Fernández-Carrasco, L., Martínez-Ramírez, S., Ibáñez, J., Artús, L., and Matschei, T. (2013b). Raman Spectroscopy of Anhydrous and Hydrated Calcium Aluminates and Sulfoaluminates. J. Am. Ceram. Soc. 96, 3589-3595. doi:10.1111/jace.12535

Tsai, Y.-L., Huang, E., Li, Y.-H., Hung, H.-T., Jiang, J.-H., Liu, T.-C., et al. (2021). Raman Spectroscopic Characteristics of Zeolite Group Minerals. Minerals 11, 167. doi:10.3390/min 11020167

van Deventer, J. S. J., White, C. E., and Myers, R. J. (2021). A Roadmap for Production of Cement and Concrete with Low-CO2 Emissions. Waste Biomass Valor. 12, 4745-4775. doi:10.1007/s12649-020-01180-5

Van Wazer, J. (1970). Equilibria and Kinetics in Inorganic Polymerizations. Inorg. Macromol. Rev. 1, 89-99.

Vinet, L., and Zhedanov, A. (2011). A 'missing' Family of Classical Orthogonal Polynomials. J. Phys. A: Math. Theor. 44, 085201. doi:10.1088/1751-8113/ $44 / 8 / 085201$

Walkley, B., San Nicolas, R., Sani, M.-A., Gehman, J. D., Van Deventer, J. S. J., and Provis, J. L. (2016). Phase Evolution of Na2O-Al2O3-SiO2-H2o Gels in Synthetic Aluminosilicate Binders. Dalton Trans. 45, 5521-5535. doi:10.1039/c5dt04878h

Wang, Y.-S., Alrefaei, Y., and Dai, J.-G. (2019). Silico-aluminophosphate and Alkali-Aluminosilicate Geopolymers: A Comparative Review. Front. Mater. 6, 106. doi:10.3389/fmats.2019.00106

Williams, R. P., Hart, R. D., and Van Riessen, A. (2011). Quantification of the Extent of Reaction of Metakaolin-Based Geopolymers Using X-ray Diffraction, Scanning Electron Microscopy, and Energy-Dispersive Spectroscopy. J. Am. Ceram. Soc. 94, 2663-2670. doi:10.1111/j.1551-2916.2011.04410.x

Winnefeld, F., Leemann, A., Lucuk, M., Svoboda, P., and Neuroth, M. (2010). Assessment of Phase Formation in Alkali Activated Low and High Calcium Fly Ashes in Building Materials. Construction Building Mater. 24, 1086-1093. doi:10.1016/j.conbuildmat.2009.11.007
Xue, X., and Stebbins, J. (1993). 23Na NMR Chemical Shifts and Local Na Coordination Environments in Silicate Crystals, Melts and Glasses. Phys. Chem. Minerals 20, 297-307. doi:10.1007/BF00215100

Yang, S., Navrotsky, A., and Phillips, B. L. (2000). In Situ Calorimetric, Structural, and Compositional Study of Zeolite Synthesis in the System 5.15Na2O-1.00Al2O3-3.28SiO2-165H2O. J. Phys. Chem. B. 104 6071-6080. doi:10.1021/jp9944278

Yao, X., Zhang, Z., Zhu, H., and Chen, Y. (2009). Geopolymerization Process of Alkali-Metakaolinite Characterized by Isothermal Calorimetry. Thermochim. Acta 493, 49-54. doi:10.1016/j.tca.2009.04.002

Yue, Y., Bai, Y., Muhammed Basheer, P. A., Boland, J. J., and Wang, J. J. (2013). Monitoring the Cementitious Materials Subjected to Sulfate Attack with Optical Fiber Excitation Raman Spectroscopy. Opt. Eng. 52, 104107. doi:10.1117/ 1.oe.52.10.104107

Yunsheng, Z., Wei, S., and Zongjin, L. (2010). Composition Design and Microstructural Characterization of Calcined Kaolin-Based Geopolymer Cement. Appl. Clay Sci. 47, 271-275. doi:10.1016/j.clay.2009.11.002

Zeng, Q., Nekvasil, H., and Grey, C. P. (2000). In Support of a Depolymerization Model for Water in Sodium Aluminosilicate Glasses:. Geochimica et Cosmochimica Acta 64, 883-896. doi:10.1016/S0016-7037(99)00352-X

Zhan, B.-Z., White, M. A., Lumsden, M., Mueller-Neuhaus, J., Robertson, K. N., Cameron, T. S., et al. (2002). Control of Particle Size and Surface Properties of Crystals of NaX Zeolite. Chem. Mater. 14, 3636-3642. doi:10.1021/cm011635f

Zhang, L., Zhang, F., Liu, M., and Hu, X. (2017). Novel Sustainable Geopolymer Based Syntactic Foams: An Eco-Friendly Alternative to Polymer Based Syntactic Foams. Chem. Eng. J. 313, 74-82. doi:10.1016/j.cej.2016.12.046

Zhang, W. F., He, Y. L., Zhang, M. S., Yin, Z., and Chen, Q. (2000). Raman Scattering Study on Anatase TiO2nanocrystals. J. Phys. D: Appl. Phys. 33, 912-916. doi:10.1088/0022-3727/33/8/305

Zhang, Z., Provis, J. L., Wang, H., Bullen, F., and Reid, A. (2013). Quantitative Kinetic and Structural Analysis of Geopolymers. Part 2. Thermodynamics of Sodium Silicate Activation of Metakaolin. Thermochim. Acta 565, 163-171. doi:10.1016/j.tca.2013.01.040

Zhang, Z., Wang, H., Provis, J. L., Bullen, F., Reid, A., and Zhu, Y. (2012). Quantitative Kinetic and Structural Analysis of Geopolymers. Part 1. The Activation of Metakaolin with Sodium Hydroxide. Thermochim. Acta 539, 23-33. doi:10.1016/j.tca.2012.03.021

Conflict of Interest: The authors declare that the research was conducted in the absence of any commercial or financial relationships that could be construed as a potential conflict of interest.

Publisher's Note: All claims expressed in this article are solely those of the authors and do not necessarily represent those of their affiliated organizations, or those of the publisher, the editors and the reviewers. Any product that may be evaluated in this article, or claim that may be made by its manufacturer, is not guaranteed or endorsed by the publisher.

Copyright (C) 2022 Abdelrahman and Garg. This is an open-access article distributed under the terms of the Creative Commons Attribution License (CC BY). The use, distribution or reproduction in other forums is permitted, provided the original author(s) and the copyright owner(s) are credited and that the original publication in this journal is cited, in accordance with accepted academic practice. No use, distribution or reproduction is permitted which does not comply with these terms. 